\title{
Cochrane
}

Library

Cochrane Database of Systematic Reviews

\section{Surgical versus non-surgical treatment for lumbar spinal stenosis} (Review)

Zaina F, Tomkins-Lane C, Carragee E, Negrini S

Zaina F, Tomkins-Lane C, Carragee E, Negrini S.

Surgical versus non-surgical treatment for lumbar spinal stenosis.

Cochrane Database of Systematic Reviews 2016, Issue 1. Art. No.: CD010264.

DOI: 10.1002/14651858.CD010264.pub2.

www.cochranelibrary.com 
TABLE OF CONTENTS

HEADER 1

ABSTRACT

PLAIN LANGUAGE SUMMARY

SUMMARY OF FINDINGS

BACKGROUND

OBJECTIVES

METHODS

RESULTS

Figure 1.

Figure 2.

Figure 3.

Figure 4.

Figure 5.

DISCUSSION

AUTHORS' CONCLUSIONS

ACKNOWLEDGEMENTS

REFERENCES

CHARACTERISTICS OF STUDIES

DATA AND ANALYSES

Analysis 1.1. Comparison 1 Decompression \pm fusion vs usual conservative care for Oswestry Disability Index, Outcome 1 Oswestry Disability Index.

Analysis 1.2. Comparison 1 Decompression \pm fusion vs usual conservative care for Oswestry Disability Index, Outcome 2 Pain.

Analysis 2.1. Comparison 2 Epidural steroid injection vs decompression with or without fusion, Outcome 1 Oswestry Disability Index.

Analysis 2.2. Comparison 2 Epidural steroid injection vs decompression with or without fusion, Outcome 2 Visual Analogue Scale.

Analysis 2.3. Comparison 2 Epidural steroid injection vs decompression with or without fusion, Outcome 3 Zurich Claudication Questionnaire.

APPENDICES

CONTRIBUTIONS OF AUTHORS

DECLARATIONS OF INTEREST

SOURCES OF SUPPORT

DIFFERENCES BETWEEN PROTOCOL AND REVIEW

INDEX TERMS 
[Intervention Review]

\section{Surgical versus non-surgical treatment for lumbar spinal stenosis}

Fabio Zaina ${ }^{1}$, Christy Tomkins-Lane ${ }^{2}$, Eugene Carragee ${ }^{3}$, Stefano Negrini ${ }^{4}$

1ISICO (Italian Scientific Spine Institute), Milan, Italy. ${ }^{2}$ Department of Health and Physical Education, Mount Royal University, Calgary,

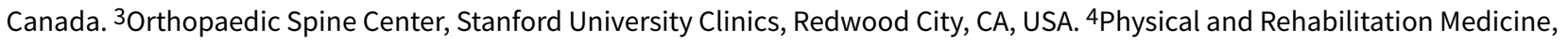
University of Brescia - IRCCS Fondazione Don Gnocchi Milan, Brescia, Italy

Contact address: Fabio Zaina, ISICO (Italian Scientific Spine Institute), Via Roberto Bellarmino 13/1, Milan, 20141, Italy. fabio.zaina@isico.it.

Editorial group: Cochrane Back and Neck Group

Publication status and date: New, published in Issue 1, 2016.

Citation: Zaina F, Tomkins-Lane C, Carragee E, Negrini S. Surgical versus non-surgical treatment for lumbar spinal stenosis. Cochrane Database of Systematic Reviews 2016, Issue 1. Art. No.: CD010264. DOI: 10.1002/14651858.CD010264.pub2.

Copyright @ 2016 The Cochrane Collaboration. Published by John Wiley \& Sons, Ltd.

\section{A B S T R A C T}

\section{Background}

Lumbar spinal stenosis (LSS) is a debilitating condition associated with degeneration of the spine with aging.

\section{Objectives}

To evaluate the effectiveness of different types of surgery compared with different types of non-surgical interventions in adults with symptomatic LSS. Primary outcomes included quality of life, disability, function and pain. Also, to consider complication rates and side effects, and to evaluate short-, intermediate- and long-term outcomes (six months, six months to two years, five years or longer).

\section{Search methods}

We searched the Cochrane Central Register of Controlled Trials (CENTRAL), MEDLINE, EMBASE, five other databases and two trials registries up to February 2015. We also screened reference lists and conference proceedings related to treatment of the spine.

\section{Selection criteria}

Randomised controlled trials (RCTs) comparing surgical versus non-operative treatments in participants with lumbar spinal stenosis confirmed by clinical and imaging findings.

\section{Data collection and analysis}

For data collection and analysis, we followed methods guidelines of the Cochrane Back and Neck Review Group (Furlan 2009) and those provided in the Cochrane Handbook for Systematic Reviews of Interventions (Higgins 2011).

\section{Main results}

From the 12,966 citations screened, we assessed 26 full-text articles and included five RCTs (643 participants).

Low-quality evidence from the meta-analysis performed on two trials using the Oswestry Disability Index (pain-related disability) to compare direct decompression with or without fusion versus multi-modal non-operative care showed no significant differences at six months (mean difference (MD) -3.66, 95\% confidence interval (Cl) -10.12 to 2.80) and at one year (MD $-6.18,95 \% \mathrm{Cl}-15.03$ to 2.66 ). At 24 months, significant differences favoured decompression (MD $-4.43,95 \% \mathrm{Cl}-7.91$ to -0.96 ). Low-quality evidence from one small study revealed no difference in pain outcomes between decompression and usual conservative care (bracing and exercise) at three months (risk ratio (RR) $1.38,95 \% \mathrm{Cl} 0.22$ to 8.59 ), four years (RR $7.50,95 \% \mathrm{Cl} 1.00$ to 56.48 ) and 10 years (RR $4.09,95 \% \mathrm{Cl} 0.95$ to 17.58 ). 
Low-quality evidence from one small study suggested no differences at six weeks in the Oswestry Disability Index for patients treated with minimally invasive mild decompression versus those treated with epidural steroid injections (MD $5.70,95 \% \mathrm{Cl} 0.57$ to $10.83 ; 38$ participants). Zurich Claudication Questionnaire (ZCQ) results were better for epidural injection at six weeks (MD $-0.60,95 \% \mathrm{Cl}-0.92$ to -0.28 ), and visual analogue scale (VAS) improvements were better in the mild decompression group (MD $2.40,95 \% \mathrm{Cl} 1.92$ to 2.88 ). At 12 weeks, many crossovers prevented further analysis.

Low-quality evidence from a single study including 191 participants favoured the interspinous spacer versus usual conservative treatment at six weeks, six months and one year for symptom severity and physical function.

All remaining studies reported complications associated with surgery and conservative side effects of treatment: Two studies reported no major complications in the surgical group, and the other study reported complications in $10 \%$ and $24 \%$ of participants, including spinous process fracture, coronary ischaemia, respiratory distress, haematoma, stroke, risk of reoperation and death due to pulmonary oedema.

\section{Authors' conclusions}

We have very little confidence to conclude whether surgical treatment or a conservative approach is better for lumbar spinal stenosis, and we can provide no new recommendations to guide clinical practice. However, it should be noted that the rate of side effects ranged from $10 \%$ to $24 \%$ in surgical cases, and no side effects were reported for any conservative treatment. No clear benefits were observed with surgery versus non-surgical treatment. These findings suggest that clinicians should be very careful in informing patients about possible treatment options, especially given that conservative treatment options have resulted in no reported side effects. High-quality research is needed to compare surgical versus conservative care for individuals with lumbar spinal stenosis.

\section{PLAIN LANGUAGE SUMMARY}

\section{Surgical versus non-surgical treatment for lumbar spinal stenosis}

Review question: We reviewed the evidence that compares surgery versus non-surgical treatment for a condition called lumbar spinal stenosis. This condition occurs when the area surrounding the spinal cord and nerves becomes smaller.

Background: People with lumbar spinal stenosis experience a range of symptoms including back pain, leg pain, numbness and tingling in the legs and reduced physical function. These symptoms prompt people to seek treatment. One option for treatment is surgery. Other treatment options include physical therapy, exercise, braces and injections into the spine.

Study characteristics: We included five studies that compared surgical versus non-surgical treatment in a total of 643 people with lumbar spinal stenosis. Average age of participants in all studies was over 59 years. Follow-up periods ranged from six weeks to 10 years.

Key results: We cannot conclude on the basis of this review whether surgical or non-surgical treatment is better for individuals with lumbar spinal stenosis. Nevertheless, we can report on the high rate of effects reported in three of five surgical groups, ranging from $10 \%$ to $24 \%$. No side effects were reported for any of the conservative treatment options.

Three studies compared spine surgery versus various types of non-surgical treatment. It is difficult for review authors to draw conclusions from these studies because non-surgical treatments were inadequately described. One study that compared surgery versus bracing and exercise found no differences in pain. Another study compared surgery versus spinal injections and found better physical function with injections, and better pain relief with surgery at six weeks. Still another trial compared surgery with an implanted device versus non-surgical care. This study reported favourable outcomes of surgery for symptoms and physical function.

Quality of the evidence: Evidence obtained by comparing surgery versus non-surgical treatment is of low quality. Well-designed studies are needed to examine this problem. In particular, researchers need to do a better job of describing the details of non-surgical treatments. 


\begin{tabular}{|c|c|c|c|c|c|}
\hline \multirow{10}{*}{ 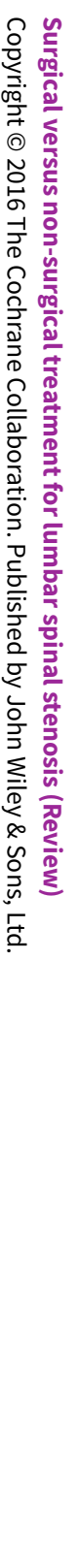 } & \multicolumn{5}{|c|}{$\begin{array}{l}\text { S U M M ARY O F F I N I NGS } \\
\text { Summary of findings for the main comparison. }\end{array}$} \\
\hline & \multicolumn{5}{|c|}{ Decompression \pm fusion vs usual conservative care for Oswestry Disabilty Index and Visual Analogue Pain Scale (VAS) for lumbar spinal stenosis } \\
\hline & \multicolumn{5}{|c|}{$\begin{array}{l}\text { Patient or population: lumbar spinal stenosis } \\
\text { Intervention: decompression } \pm \text { fusion } \\
\text { Comparison: usual conservative care }\end{array}$} \\
\hline & Outcomes & $\begin{array}{l}\text { Relative effect } \\
(95 \% \mathrm{Cl})\end{array}$ & Outcome means & $\begin{array}{l}\text { Number of } \\
\text { participants } \\
\text { (studies) }\end{array}$ & $\begin{array}{l}\text { Quality of the } \\
\text { evidence } \\
\text { (GRADE) }\end{array}$ \\
\hline & $\begin{array}{l}\text { Oswestry Disability Index - } 6 \\
\text { months } \\
\text { (0 to } 100 \%)\end{array}$ & (MD $-3.66 \%, 95 \% \mathrm{Cl}-10.12$ to 2.80$)$ & $\begin{array}{l}\text { Decompression range: } 20.7 \text { to } 28.1 \\
\text { Usual conservative care range: } 28.3 \text { to } \\
29.0\end{array}$ & $349(2)$ & $\begin{array}{l}\oplus \oplus \ominus \ominus \\
\text { Low }\end{array}$ \\
\hline & $\begin{array}{l}\text { Oswestry Disability Index - } 1 \text { year } \\
\text { (0 to } 100 \%)\end{array}$ & (MD $-6.17 \%, 95 \% \mathrm{Cl}-15.02$ to 2.67 ) & $\begin{array}{l}\text { Decompression range: } 18.9 \text { to } 27.8 \\
\text { Usual conservative care range: } 30.0 \text { to } \\
30.2\end{array}$ & $340(2)$ & $\begin{array}{l}\oplus \oplus \ominus \ominus \\
\text { Low }\end{array}$ \\
\hline & $\begin{array}{l}\text { Oswestry Disability Index - } 2 \\
\text { years } \\
\text { (0 to } 100 \%)\end{array}$ & (MD $-4.43 \%, 95 \% \mathrm{Cl}-7.91$ to -0.96$)$ & $\begin{array}{l}\text { Decompression range: } 21.2 \text { to } 26.3 \\
\text { Usual conservative care range: } 29 \text { to } 29.8\end{array}$ & $315(2)$ & $\begin{array}{l}\oplus \oplus \ominus \ominus \\
\text { Low }\end{array}$ \\
\hline & $\begin{array}{l}\text { Pain - } 3 \text { months } \\
\text { (0 to } 10)\end{array}$ & (RR $1.38,95 \% \mathrm{Cl} 0.22$ to 8.59$)$ & $\begin{array}{l}\text { Decompression: } 5.45 \\
\text { Usual conservative care: } 2.81\end{array}$ & $31(1)$ & $\begin{array}{l}\oplus \oplus \ominus \ominus \\
\text { Low }\end{array}$ \\
\hline & $\begin{array}{l}\text { Pain }-4 \text { years } \\
\text { (0 to } 10)\end{array}$ & (RR $7.50,95 \% \mathrm{Cl} 1.00$ to 56.48$)$ & $\begin{array}{l}\text { Decompression: } 5.05 \\
\text { Usual conservative care: } 2.72\end{array}$ & $30(1)$ & $\begin{array}{l}\oplus \oplus \ominus \ominus \\
\text { Low }\end{array}$ \\
\hline & $\begin{array}{l}\text { Pain } \mathbf{- 1 0} \text { years } \\
(0 \text { to } 10)\end{array}$ & (RR $4.09,95 \% \mathrm{Cl} 0.95$ to 17.58$)$ & $\begin{array}{l}\text { Decompression: } 4.87 \\
\text { Usual conservative care: } 2.74\end{array}$ & $29(1)$ & $\begin{array}{l}\oplus \oplus \ominus \ominus \\
\text { Low }\end{array}$ \\
\hline
\end{tabular}

Cl: confidence interval; $\mathbf{M D}$ : mean difference; $\mathbf{R R}$ : risk ratio

GRADE Working Group grades of evidence

High quality: Further research is very unlikely to change our confidence in the estimate of effect 
Moderate quality: Further research is likely to have an important impact on our confidence in the estimate of effect and may change the estimate Low quality: Further research is very likely to have an important impact on our confidence in the estimate of effect and is likely to change the estimate Very low quality: We are very uncertain about the estimate

Studies failed on 3 of 5 GRADE factors, including:

- bias: All but 1 study had high bias risk;

- design: All but 1 study were not blinded; and

- imprecision: Only 1 study presented compete outcome data.

\section{Summary of findings 2 .}

\section{Epidural steroid injection vs mild decompression + fusion for lumbar spinal stenosis}

Patient or population: lumbar spinal stenosis

Intervention: epidural steroid injection

Comparison: decompression \pm fusion

\begin{tabular}{|c|c|c|c|c|c|}
\hline Outcomes & $\begin{array}{l}\text { Relative effect } \\
(95 \% \mathrm{Cl})\end{array}$ & Outcome means & $\begin{array}{l}\text { Number of } \\
\text { participants } \\
\text { (studies) }\end{array}$ & $\begin{array}{l}\text { Quality of the } \\
\text { evidence } \\
\text { (GRADE) }\end{array}$ & Comments \\
\hline Oswestry Disability Index - 6 weeks & (MD 5.70, $95 \% \mathrm{Cl} 0.57$ to 10.83 ) & $\begin{array}{l}\text { Epidural injection: } 34.8 \\
\text { Mild decompression: } 27.4\end{array}$ & $38(1)$ & $\begin{array}{l}\oplus \oplus \ominus \ominus \\
\text { Low }\end{array}$ & \\
\hline $\begin{array}{l}\text { Visual Analogue Scale (VAS) - } 6 \\
\text { weeks }\end{array}$ & (MD $2.40,95 \% \mathrm{Cl} 1.92$ to 2.88 ) & $\begin{array}{l}\text { Epidural injection: } 6.3 \\
\text { Mild decompression: } 3.8\end{array}$ & $38(1)$ & $\begin{array}{l}\oplus \oplus \ominus \ominus \\
\text { Low }\end{array}$ & \\
\hline $\begin{array}{l}\text { Zurich Claudication Questionnaire - } \\
6 \text { weeks }\end{array}$ & (MD $-0.60,95 \% \mathrm{Cl}-0.77$ to -0.43 ) & $\begin{array}{l}\text { Epidural injection: } 2.8 \\
\text { Mild decompression: } 2.2\end{array}$ & $38(1)$ & $\begin{array}{l}\oplus \oplus \ominus \ominus \\
\text { Low }\end{array}$ & \\
\hline
\end{tabular}

Cl: confidence interval; MD: mean difference

GRADE Working Group grades of evidence

High quality: Further research is very unlikely to change our confidence in the estimate of effect

Moderate quality: Further research is likely to have an important impact on our confidence in the estimate of effect and may change the estimate

Low quality: Further research is very likely to have an important impact on our confidence in the estimate of effect and is likely to change the estimate

Very low quality: We are very uncertain about the estimate

Although this study had low risk of bias, this was the only study examined. Further research is very likely to have an impact on our confidence 


\section{B A C K G R O U N D}

Lumbar spinal stenosis (LSS) is "a clinical syndrome of buttock or lower extremity pain, which may occur with or without back pain, associated with diminished space available for the neural and vascular elements in the lumbar spine" (Watters 2008). LSS can be classified as congenital (developmental), acquired or both (Botwin 2007). Most cases of LSS occur as acquired degenerative stenosis, resulting from aging of the spine or following surgery or infection (Chad 2007; Ciricillo 1993). Mixed stenosis occurs when degenerative changes exacerbate existing congenital stenosis (Ciricillo 1993). Regardless of the aetiology, this condition can cause chronic pain and disability, dramatically reducing quality of life, mobility and function (Chad 2007).

Recent advances in imaging technology, improvements in diagnostic accuracy and aging of the population have contributed to a marked increase in the diagnosis of LSS (Benoist 2002; Haig 2006; Lurie 2003). LSS has become one of the conditions seen most frequently in orthopaedic and neurosurgical practice (Deyo 2006) and is the most common reason for spine surgery among individuals over the age of 65 years (Deyo 2010). Although the overall rate of surgery for LSS appears to have declined slightly between 2002 and 2007, the rate of complex fusion procedures increased 15-fold (Deyo 2010). As such, LSS is, and will continue to be, associated with significant healthcare costs (Ciol 1996; Fanuele 2000; Taylor 1994). Given the significant economic ramifications associated with treatment for individuals with this increasingly prevalent diagnosis, identification of effective treatment options for this population is a matter of priority (Whitman 2003).

\section{Description of the condition}

Anatomically, LSS refers to narrowing of the central spinal canal, lateral recesses or intervertebral foramen, causing compression of associated neurovascular structures. Degenerative lumbar stenosis results from changes in the spine that occur with aging, including facet joint hypertrophy, loss of intervertebral disc height, disc bulging, osteophyte formation and hypertrophy of the ligamentum flavum (Atlas 2006). The hallmark of spinal stenosis is neurogenic claudication, consisting of lower limb pain and neurological symptoms exacerbated by walking (Chad 2007; Porter 1996). Accordingly, because of pain and discomfort in the lower extremities, people with LSS often avoid walking and have reduced walking capacity (Iversen 2001; Tomkins-Lane 2012). Patients with LSS also report physical impairments including poor balance, sensory loss (numbness or tingling) and muscle weakness in the buttocks and lower extremities (Iversen 2001; Johnsson 1987; Stucki 1995). Symptoms generally are intermittent and posture dependent, appearing with standing and lumbar extension, exacerbated by walking and relieved by rest in a flexed or seated position (Binder 2002; Chad 2007). Radicular pain may be due to a combination of mechanical compression, inflammatory irritation of neural elements, vascular congestion and segmental instability (Carragee 2010). No 'gold standard' for diagnosis of clinical LSS is known; therefore inclusion criteria for studies to date have been heterogeneous. This is one limitation of meta-analysis of studies including participants with LSS.

\section{Description of the intervention}

Possible surgical procedures for spinal stenosis include laminectomy, fusion, minimally invasive implants, spinal devices and prostheses (Postacchini 1999). Conservative treatments include exercise, manipulation, mobilisation, physical therapy, drugs, acupuncture, bracing, education and cognitive-behavioural treatments (Haig 2010).

\section{How the intervention might work}

Surgery can increase the amount of space in the spinal canal through removal of portions of the posterior spinal elements (laminae, facets, osteophytes, ligaments, synovitis or synovial cysts); generally this is referred to as 'decompression'. Removal of these pathological compressive structures may exacerbate existing instability or create de novo instability following decompression. Spinal fusion is sometimes added to the decompression procedure to avoid or treat this instability. Alternatively, spinal instrumentation in the form of posterior spacers may be placed to alter spinal alignment without fusion, to achieve a position of empirical pain relief. In most patients, this position is characterised by relative flexion and posterior decompression of the stenotic segment achieved without disruption of normal anatomical structures. Thus, the goal of surgery is to create a relative flexion to open the foramina without modifying anatomy at the stenotic level (Carragee 2010).

Conservative treatment can act on pain perception directly (drugs, physical therapy, acupuncture), or it can improve mobility and control of movement in the lumbar spine (Negrini 2006), both actively (exercise) and passively (manipulation, mobilisation). Education and cognitive-behavioural treatments can improve pain and quality of life by giving patients information about their condition and about its management, thereby promoting healthy behaviours. Physical activity can improve overall health and potentially leads to reduced pain and improved function (TomkinsLane 2015). These latter treatments are frequently administered together with other approaches to act on both psychological and physical aspects of the problem.

\section{Why it is important to do this review}

Non-surgical interventions are almost always initially recommended in the treatment of patients with LSS (Negrini 2010), but surgery is generally considered the gold standard. Only a few studies have compared surgical and non-surgical treatments, and study findings are inconsistent (Kovacs 2011; Negrini 2010). Surgery can lead to side effects including spinal instability that necessitate further operative treatment (frequently spinal fusion). Generally speaking, the risk of reoperation is approximately $17 \%$ (Deyo 2011). New techniques such as insertion of interspinous stand-alone spacers have shown a high rate of reoperation, with as many as $27 \%$ of patients undergoing a second operation in the first year (Sobottke 2010). Even worse, some studies have reported really high risk of major medical complications associated with surgery, including an overall $3.1 \%$ risk of cardiopulmonary complications or stroke, and a $0.4 \%$ risk of death within one month, especially when patients present with co-morbidities (Deyo 2010). At the same time, evidence regarding conservative treatment has been limited and vague (Atlas 2006 Tomkins 2010; Tomkins-Lane 2012).

For these reasons, a reliable comparison of treatments is needed. 


\section{O B JECTIVES}

To evaluate the effectiveness of different types of surgery compared with different types of non-surgical interventions in adults with symptomatic lumbar spinal stenosis (LSS). Primary outcomes included quality of life, disability, function and pain. Also, to consider complication rates and side effects, and to evaluate short-, intermediate- and long-term outcomes (six months, six months to two years, five years or longer).

\section{METHODS}

\section{Criteria for considering studies for this review Types of studies}

We considered for inclusion both randomised controlled trials (RCTs) and quasi-randomised controlled studies comparing surgical procedures versus non-surgical treatments. Randomised studies are those in which participants are selected truly at random with a computer-generated sequence used to assign participants, or closed envelopes, block randomisations and similar approaches. Quasi-randomised studies are those in which the method of allocating participants to treatment is not strictly random, for example, by date of birth, hospital record number or alternation.

\section{Types of participants}

We included studies involving adult patients older than 18 years of age, with age stratified in the analysis. We applied no limitations on gender or age. We defined inclusion by both clinical findings and imaging. We defined the symptom and sign complex indicating high confidence in the diagnosis of 'symptomatic LSS' as either neurogenic claudication or monoradicular or polyradicular symptoms that are neuro-anatomically consistent with an area of pathological stenosis. We needed images to clearly show congenital or degenerative narrowing, or both, of the spinal canal with displacement or compression or deformity of neural elements. When patients presented with some degree of degenerative spondylolisthesis, we included them only when they also presented with primary neurological claudication or radicular symptoms. We excluded those with non-specific low back pain and radicular pain secondary to primary pathological conditions other than congenital or degenerative LSS. Excluded conditions were isthmic spondylolisthesis, disc herniation and post-fracture stenosis. For studies including mixed clinical populations, we contacted study authors to collect data on eligible patients. When we received no answer, or when subgroups were not included, we excluded those studies.

\section{Types of interventions}

We included all types of surgical procedures (decompression, spinal fusion, any kind of device or prosthesis) compared with all types of non-surgical procedures (e.g. exercise, manipulation, mobilisation, physical therapy, drugs, acupuncture, bracing, education and cognitive-behavioural treatments). We did not group interventions together but separately evaluated the effectiveness of different types of surgical procedures versus different types of non-surgical interventions.

\section{Types of outcome measures}

\section{Primary outcomes}

- Disability and functional status, as measured by a back pain-specific scale (e.g. Roland-Morris Disability Questionnaire (RMDQ), Oswestry Disability Index (ODI)).

- Pain intensity, as measured by a visual analogue or other pain scale (e.g. visual analogue scale (VAS), numerical rating scale (NRS), McGill Pain Scale).

- Health-related quality of life (e.g. Short Form (SF)-36 (as measured by the general health subscale), European Organization for Research and Treatment of Cancer Core Quality of Life Questionnaire (EuroQol), general health (e.g. as measured on a VAS scale) or a similarly validated index).

- Walking capacity (e.g. walking distance before participant is forced to stop because of symptoms of LSS).

\section{Secondary outcomes}

Secondary outcome measures included side effects, complications, failure rates and patient satisfaction. Side effects and complications could be injuries secondary to the intervention, including infection, neurological damage and worsening of symptoms.

Assessment was considered according to the amount of time that had passed since the intervention was provided (i.e. short-term: six months; intermediate: up to 24 months; long-term: five years or longer).

\section{Search methods for identification of studies}

\section{Electronic searches}

We used the updated search strategy recommended by the Cochrane Back and Neck Review Group for identifying RCTs (Furlan 2009), combined with the strategy developed for the review of nonoperative treatments for spinal stenosis conducted by Ammendolia et al (Ammendolia 2011).

We performed a comprehensive search up to 11 February 2015 to identify all relevant studies included in the following electronic databases.

- Cochrane Central Register of Controlled Trials (CENTRAL) (January 2015, Issue 1 of 12).

- MEDLINE (Ovid SP, 1946 to Week 1 February 2015) and MEDLINE In-Process \& Other Non-Indexed Citations (Ovid SP, 10 February 2015).

- EMBASE (Ovid SP, 1980 to Week 7 2015) (on 19 February 2015).

- Cumulative Index to Nursing and Allied Health Literature (CINAHL; EBSCO, 1981 to 11 February 2015).

- Index to Chiropractic Literature (ICL).

- Physiotherapy Evidence Database (PEDro).

- ClinicalTrials.gov.

- World Health Organization (WHO) International Clinical Trials Registry Platform (ICTRP).

- PubMed.

- Cochrane Back and Neck Review Group Trials Register (Cochrane Register of Studies (CRS)). 
For the 2015 search, we added ClinicalTrials.gov and WHOICTRP to identify ongoing trials; we searched PubMed for studies not included in MEDLINE by using the strategy devised by Duffy 2014, and we searched the Cochrane Back and Neck Review Group Trials Register in the CRS for studies not found in CENTRAL. Full search strategies can be found in Appendix 1. We placed no limitations on language or date.

\section{Searching other resources}

We performed a handsearch and an electronic search for conference proceedings related to treatment of the spine. We also screened reference lists.

\section{Data collection and analysis}

For data collection and analysis, we followed methods guidelines of the Cochrane Back and Neck Review Group (Furlan 2009) and those provided in the Cochrane Handbook for Systematic Reviews of Interventions (Higgins 2011).

\section{Selection of studies}

Two independent review authors evaluated search results by reading the titles and abstracts. We obtained the full text of potentially relevant studies and independently assessed them for inclusion. We resolved disagreements through discussion with a third review author.

\section{Data extraction and management}

Two independent review authors performed data extraction using a standardised form to report the most relevant details (Furlan 2009). Extracted data included characteristics of the population, types of interventions provided, duration of treatment and followup periods and the outcome measures listed above. We reported all data via a specific Excel form designed for the purpose.

\section{Assessment of risk of bias in included studies}

At least two review authors independently assessed risk of study bias (Furlan 2009). We evaluated possible bias due to generation of the allocation sequence, concealment of allocation, blinding, incomplete outcome data, selective outcome reporting and other sources of bias (see Appendix 2). In cases of disagreement, the two review authors discussed the assessment and reached a shared decision. We did not assess inter-author reliability because we reached agreement on each study evaluation. We scored each criterion as having high risk, low risk or unclear risk according to the criteria provided in the Cochrane Handbook for Systematic Reviews of Interventions (Higgins 2011).

\section{Measures of treatment effect}

We analysed dichotomous outcomes by calculating the risk ratio (RR) for each trial and expressing the uncertainty in each result through 95\% confidence intervals (Cls). We analysed continuous outcomes by calculating mean differences (MDs) for studies that used the same instrument to measure the outcome, and we used standardised mean differences (SMDs) with $95 \%$ Cls for studies that used different instruments.

We determined clinical relevance as defined by the following pooled effect sizes.
- Small: $\mathrm{MD}<10 \%$ of the scale (e.g. $<10 \mathrm{~mm}$ on a $100-\mathrm{mm}$ VAS); $\mathrm{SMD}<0.4 ; \mathrm{RR}<1.25$ or $>0.8$ (depending on whether risk or benefit was reported for the intervention or control group).

- Medium: MD $10 \%$ to $20 \%$ of the scale; SMD 0.41 to 0.7 ; RR 1.25 to 2.0 or 0.5 to 0.8 .

- Large: $\mathrm{MD}>20 \%$ of the scale; $\mathrm{SMD}>0.7$; RR $>2.0$ or $<0.5$ (Higgins 2011).

Review authors assessed the clinical relevance of each included study by using the five questions outlined in Appendix 3 (Furlan 2009).

\section{Dealing with missing data}

In cases of incomplete and missing data, we contacted the authors of all included studies. We assessed missing data and dropouts or attrition for each included study, and we discussed and evaluated the extent to which results and conclusions of the review were altered by missing data. To avoid potential bias, we did not use outcomes for which less than $70 \%$ of participants allocated to treatment were reported on at the end of the trial. When data were reported as median and interquartile range (IQR), we assumed that the median was equivalent to the mean and that the width of the IQR was equivalent to 1.35 times the standard deviation (Higgins 2011). In studies presenting a range along with the median instead of an IQR, we estimated the standard deviation as one-quarter of the range (Higgins 2011). When data were reported in a graph and not in a table, we estimated means and standard deviations. When standard deviations were not reported, we attempted to contact the study authors. When the standard deviation for followup measurements was missing, we used the baseline measure for subsequent follow-ups. Finally, when no measure of variation was reported anywhere in the text, we estimated the standard deviation on the basis of findings of other studies with similar populations and risk of bias.

\section{Assessment of heterogeneity}

We used a Chi2 test to assess for heterogeneity (Higgins 2011). A P value of the $\mathrm{Chi}^{2}$ test less than 0.05 indicates significant statistical heterogeneity. We performed the meta-analysis by pooling data only in cases of clinically homogeneous data.

\section{Assessment of reporting biases}

We used a funnel plot to assess the presence of reporting biases. We evaluated whether asymmetry was due to publication bias or to a relationship between trial size and effect size (Higgins 2011).

\section{Data synthesis}

We combined outcome measures from individual trials through meta-analysis when possible (clinical comparability of populations, interventions and outcomes between trials) by using a random-effects model.

When meta-analysis was not possible, we qualitatively described the results.

We assessed the overall quality of the evidence for each outcome by using the GRADE (Grades of Recommendation, Assessment, Development and Evaluation) approach, as recommended in the Cochrane Handbook for Systematic Reviews of Interventions (Higgins 2011) and adapted in the updated method guidelines of the Cochrane Back and Neck Review Group (Furlan 2009). Factors 
that may decrease the quality of the evidence include study design and risk of bias, inconsistency of results, indirectness (not generalisable), imprecision (sparse data) and others (e.g. reporting bias). We downgraded the quality of the evidence for a specific outcome according to the performance of studies against these five factors.

- High-quality evidence: consistent findings among at least $75 \%$ of RCTs with low risk of bias; consistent, direct and precise data; no known or suspected publication biases. Further research is unlikely to change the estimate or our confidence in the results.

- Moderate-quality evidence: one of the domains not met. Further research is likely to have an important impact on our confidence in the estimate of effect and may change the estimate.

- Low-quality evidence: two of the domains not met. Further research is very likely to have an important impact on our confidence in the estimate of effect and is likely to change the estimate.

- Very low-quality evidence: three of the domains not met. We are very uncertain about the results.

- No evidence: No RCTs were identified that addressed this outcome

\section{Subgroup analysis and investigation of heterogeneity}

Given that we conducted the meta-analysis using only two studies, it was not appropriate to conduct subgroup analyses (Malmivaara 2007; Weinstein 2008).

\section{Sensitivity analysis}

Both studies included in the meta-analysis had similar risk of bias; therefore, we did not expect differences in treatment effects based on bias, and we did not conduct sensitivity analyses (Malmivaara 2007; Weinstein 2008).

\section{RESULTS}

\section{Description of studies}

A total of five randomised controlled trials (10 references) met the inclusion criteria, were included in this review (Amundsen 2000; Brown 2012; Malmivaara 2007; Weinstein 2008; Zucherman 2004) and are described under Characteristics of included studies. Studies included a total of 643 participants, and each study compared some form of surgical intervention versus non-operative treatment. Investigators randomly assigned 322 participants to surgical intervention and 321 to non-operative treatment. The mean age of participants was over 59 years in all studies. The overall percentage of male participants was $54 \%$. Follow-up periods varied significantly and ranged from six weeks to 10 years. One of the five studies was blinded (Brown 2012).

\section{Results of the search}

From the 12,966 citations screened, we assessed 26 full-text articles and included five RCTs ( 10 references). We found one ongoing study (Overdevest 2011) and added another study to studies awaiting classification (Delitto 2015). (Figure 1). 
Figure 1. Study flow diagram.

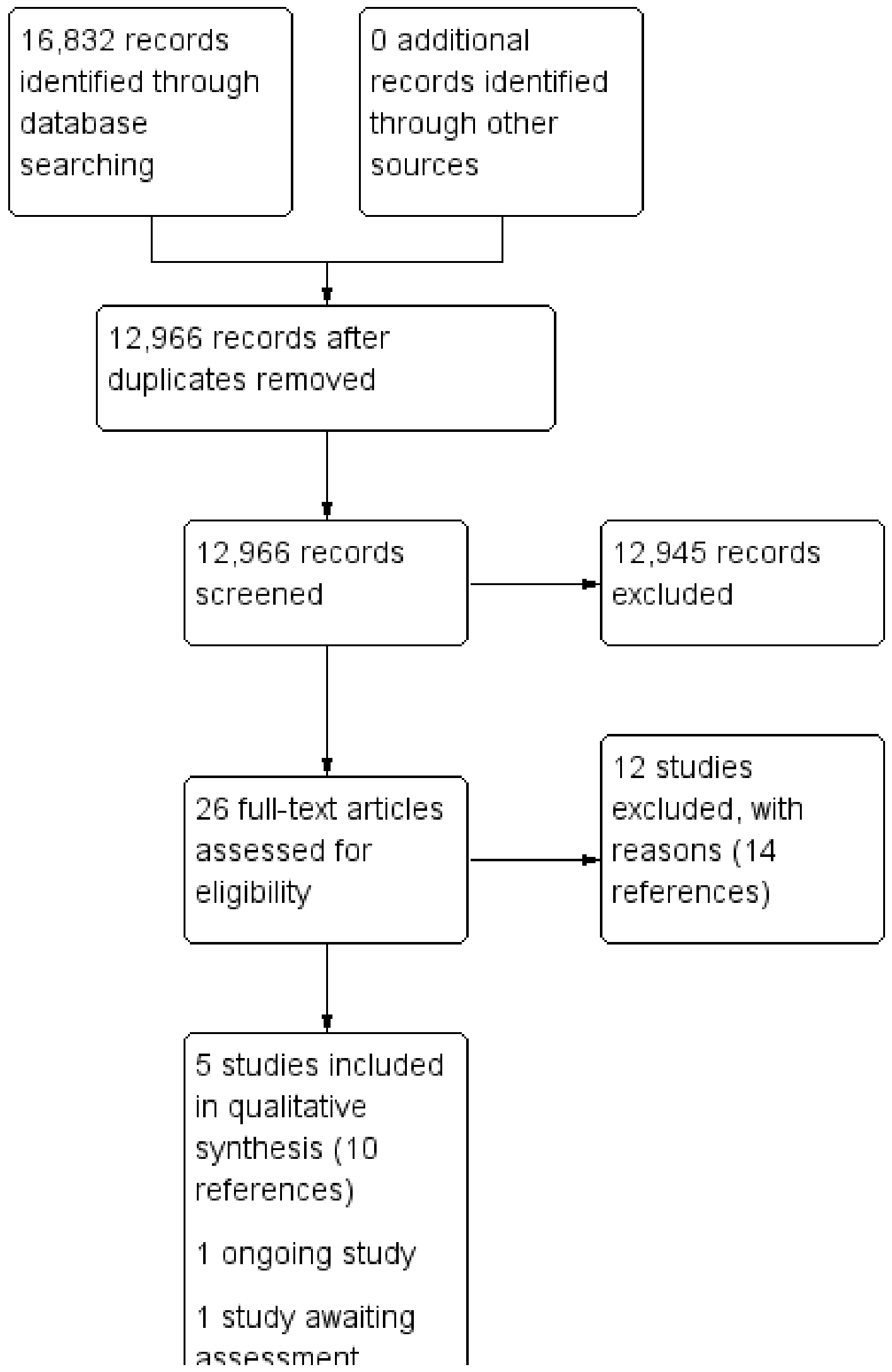


Figure 1. (Continued)

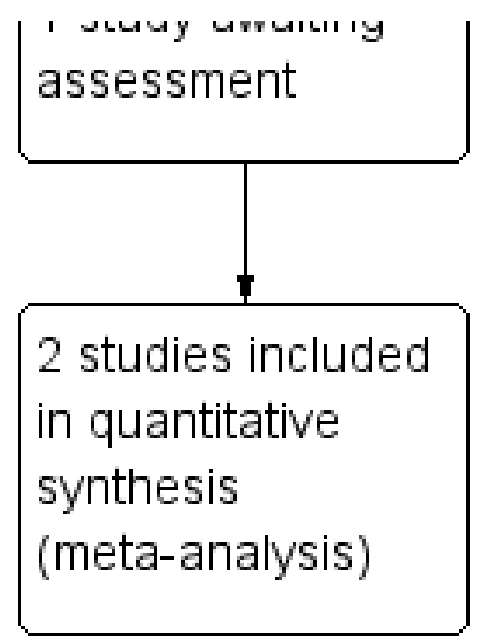

\section{Included studies}

\section{Types of studies}

All studies were randomised controlled trials (RCTs). Two also included an observational arm that was excluded from the analysis (Amundsen 2000, Weinstein 2008). Included studies are described under Characteristics of included studies.

\section{Study populations}

All participants had lumbar spinal stenosis confirmed by clinical findings and by imaging.

\section{Techniques}

Surgical techniques and types of non-operative treatment varied.

\section{Outcome measures}

Outcomes included the Oswestry Disability Index (ODI), visual analogue pain scales (VASs), the Zurich Claudication/Swiss Spinal Stenosis Questionnaire, walking ability and Short-Form 36 (SF-36).

A brief summary of the five included studies follows here.

Amundsen 2000 was an RCT that included 100 participants with LSS. Participants were 54 men and 46 women whose median age was 59 years. From these individuals, investigators selected a group $S(n=19)$ for surgical treatment because of the severity of their symptoms and a group $C(n=50)$, with milder pain, for conservative treatment. They assigned remaining participants to group $R(n=31)$ when severity of pain left the physician in doubt concerning which treatment to recommend, then to surgical treatment group RS ( $n=13$ ) or conservative treatment group RC $(n=18)$. The surgical procedure was standardised for the purpose of nerve decompression by partial or total laminectomy, medial facetectomy or discectomy. For conservative care, patients were fitted with an orthosis and were transferred to the rehabilitation department for one month. Outcomes included visual analogue pain scale, verbal rating scale, subjective change (better, worse or unchanged), work status and subjective physician rating (excellent, fair, unchanged, worse) at six months, 12 months, four years and 10 years.
Brown 2012 was a double-blind, randomised, prospective study of 38 participants with LSS. Investigators randomly assigned participants to two treatment groups, with 21 included in the surgery group and 17 in the epidural steroid treatment group. The surgical group received the minimally invasive mild decompression procedure, and the conservative group underwent the epidural steroid injection procedure. Outcomes included visual analogue pain scale, Oswestry Disability Index and Zurich Claudication Questionnaire at six weeks and at 12 weeks.

Malmivaara 2007 was an RCT of 94 participants with LSS. Researchers randomly assigned 50 participants (age $62 \pm 9$ years) to the surgical group and 44 (age $63 \pm 9$ ) to the non-operative treatment group. The surgical group underwent segmental decompression and an undercutting facetectomy of the affected area. When indicated, investigators prescribed participants in the conservative treatment group non-steroidal anti-inflammatory drugs and referred them to physiotherapists. Participants were seen one to three times by a physiotherapist, in addition to the standard visit provided at each follow-up occasion. Outcomes included an 11-point numerical pain scale for leg and back, Oswestry Disability Index, walking ability (distance without a break measured by treadmill) and general health status at six, 12 and 24 months.

Weinstein 2008 was a multi-centre RCT of 289 participants with LSS with a mean age of $65.5 \pm 10.5$ years; $38 \%$ were female. Of these participants, 138 were assigned to the surgical group, and 151 to the non-surgical group. The protocol for surgery consisted of standard posterior decompressive laminectomy. The non-surgical protocol provided "usual care", which was recommended to include at least active physical therapy, education or counselling with home exercise instruction and administration of non-steroidal anti-inflammatory drugs, if tolerated. Outcomes included SF-36, Oswestry Disability Index (MODEMS version), Low Back Pain Bothersomeness Scale, Leg Pain Bothersomeness Scale, Stenosis Bothersomeness Index and self reported satisfaction at six weeks, three months, six months and one, two and four years.

Zucherman 2004 was a multi-centre RCT of 191 participants with LSS, among whom 100 were randomly assigned to the $X$ STOP surgical procedure group, and 91 to the conservative care group. Individuals enrolled in the X STOP group underwent surgery for 
implantation of an interspinous implant. Those randomly assigned to the conservative care group received at least one epidural steroid injection and could receive non-steroidal anti-inflammatory drugs, analgesics and physical therapy. Physical therapy consisted of back school and modalities such as ice packs, heat packs, massage, stabilisation exercises and pool therapy. Braces, such as abdominal binders and corsets, were permitted, but body jackets and chair-back braces were not allowed. Outcomes included SF-36, Zurich Claudication Questionnaire (ZCQ), Oswestry Disabilty Index, Worker's Compensation claim and radiographic changes at six weeks, six months and one year.

\section{Excluded studies}

Of 26 full-text studies, we excluded 14 . We excluded 7 studies (9 references) because participants were not randomly assigned
(Athiviraham 2007; Atlas 1996; Chang 2005; Hurri 1998; Mariconda 2002; Ohtori 2014; Paker 2005) and one study because it included mixed populations (Pearson 2011). One was a commentary (no original data) (Malmivaara 2007a), one was a review (Croft 2012), one evaluated cost-effectiveness, which was not an outcome of interest for this review (Tosteson 2011), and one was a cohort study (Keller 1996). Reasons for exclusion of studies can be found in the table Characteristics of excluded studies.

\section{Risk of bias in included studies}

We found only one study to have an overall low risk of bias (Brown 2012) (Figure 2, Figure 3).

\section{Figure 2. Risk of bias graph: review authors' judgements about each risk of bias item presented as percentages} across all included studies.

\section{Random sequence generation (selection bias)}

Allocation concealment (selection bias)

Blinding (performance bias and detection bias)

Incomplete outcome data (attrition bias)

Selective reporting (reporting bias)

Group similarity at baseline (selection bias)

Co-interventions (performance bias)

Compliance (performance bias)

Intention-to-treat-analysis

Timing of outcome assessments (detection bias)

Other bias
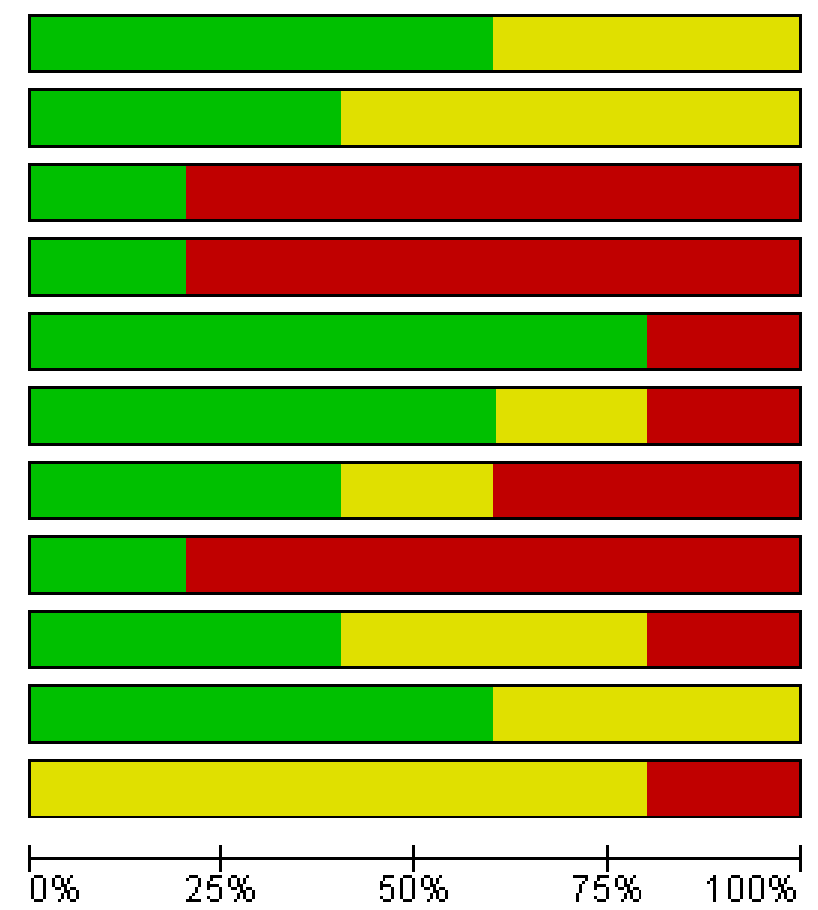

Low risk of bias

Unclear risk of bias

High risk of bias 
Figure 3. Risk of bias summary: review authors' judgements about each risk of bias item for each included study.

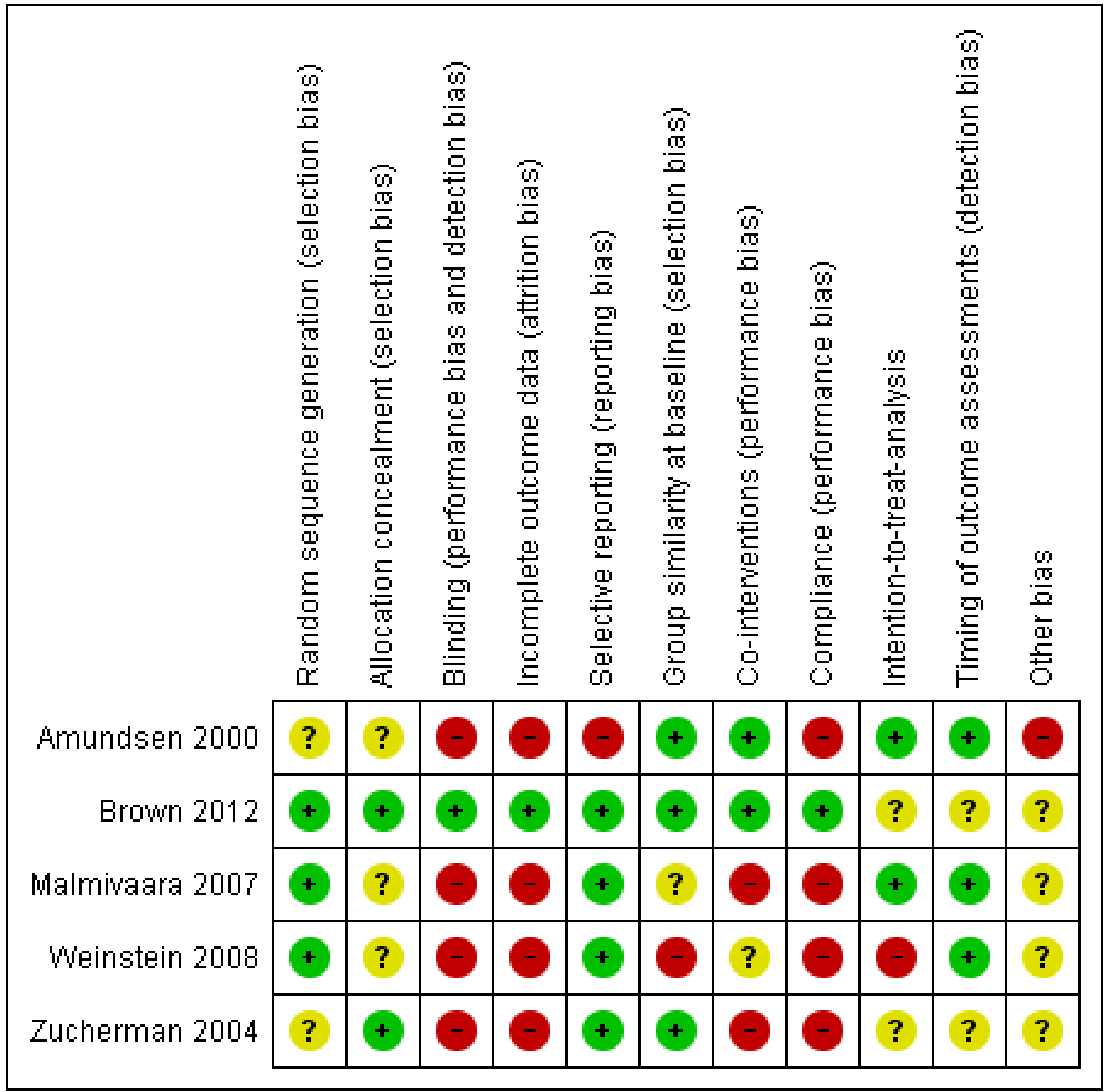

\section{Random sequence generation (selection bias)}

Three studies clearly described low risk of bias for the randomisation process (Brown 2012; Malmivaara 2007, Weinstein 2008), and the other two studies (Amundsen 2000; Zucherman 2004) did not provide this information.

\section{Allocation}

We considered allocation to be adequate in two studies (Brown 2012; Zucherman 2004) and unclear in the other three studies, given that study authors did not provide the required information (Amundsen 2000; Malmivaara 2007; Weinstein 2008).

\section{Blinding}

Blinding is very difficult when surgical and non-surgical treatments are compared because of the nature of the interventions. It is obvious in most cases to participants whether they are undergoing surgical or non-surgical care. Only one study was double-blinded, and it was rated as having low risk bias for this criterion (Brown 2012). The other four studies (Amundsen 2000; Malmivaara 2007; Weinstein 2008; Zucherman 2004) were considered at high risk of bias for this criterionbecause blinding was not possible, given the types of interventions compared.

\section{Incomplete outcome data}

Only one study presented complete data and was considered at low risk bias for this criterion (Brown 2012). Three studies (Amundsen 2000; Malmivaara 2007; Zucherman 2004) were considered at high risk of bias because study authors reported only data for completers. One study (Weinstein 2008) was rated at high risk of bias because the number of cross-overs made complete outcome reporting impossible after the first phase. 


\section{Selective reporting}

Four studies reported all outcomes presented in the protocol and were considered at low risk (Brown 2012; Malmivaara 2007; Weinstein 2008; Zucherman 2004). We considered one study to be at high risk (Amundsen 2000) because not all outcomes were reported.

\section{Group similarity at baseline (selection bias)}

Groups were similar at baseline for each comparison.

\section{Co-interventions (performance bias)}

We noted no imbalance among co-interventions.

\section{Compliance (performance bias)}

Risk of bias was unclear in four studies because compliance was not monitored in the conservative group.

\section{Intention-to-treat analysis}

In one study, no intent-to-treat analysis (ITT) was performed because of the high rate of cross-over; therefore, the study was considered to be at high risk (Weinstein 2008).

\section{Timing of outcome assessments (detection bias)}

Risk of bias was low because all important outcome assessments for all intervention groups were measured at the same time.

\section{Other potential sources of bias}

We found no further risks of bias.

\section{Effects of interventions}

See: Summary of findings for the main comparison; Summary of findings 2
We pooled two of the included studies together for a single outcome - the Oswestry Disability Index (Malmivaara 2007; Weinstein 2008; Analysis 1.1). We presented data for the other three studies (Amundsen 2000; Brown 2012; Zucherman 2004) individually because of heterogeneity of interventions, study populations, outcome measures and duration of follow-up.

\section{Usual conservative treatment versus decompression with or without fusion}

Three studies (414 participants) compared usual conservative treatment versus decompression with or without fusion (Amundsen 2000; Malmivaara 2007; Weinstein 2008). The surgical approach consisted of decompression through laminectomy and eventually spinal fusion in cases of risk of instability. Usual conservative treatment consisted of varying approaches including non-steroidal anti-inflammatory drugs, exercise, education, steroid injections and other modalities. For each case, investigators presented no clearly defined standard protocol and no description of the specifics of conservative treatment.

We obtained low-quality evidence from the meta-analysis performed with two trials (320 participants) for the Oswestry Disability Index (pain-related disability), comparing direct decompression with or without fusion versus multi-modal nonoperative care (Malmivaara 2007; Weinstein 2008) (Figure 4). Investigators reported no significant differences at six months (mean difference (MD) $-3.66,95 \%$ confidence interval (Cl) -10.12 to 2.80 ) and at one year (MD -6.18,95\% Cl-15.03 to 2.66). At 24 months, they found a significant difference favouring decompression (MD $-4.43,95 \% \mathrm{Cl}-7.91$ to -0.96$)$. Longer follow-up data are available for only one study, so it was not possible for review authors to conduct this combined analysis.

\section{Figure 4. Forest plot of comparison: 1 Decompression \pm fusion vs usual non-operative care for Oswestry Disability} Index, outcome: 1.1 Oswestry Disability Index [\%].

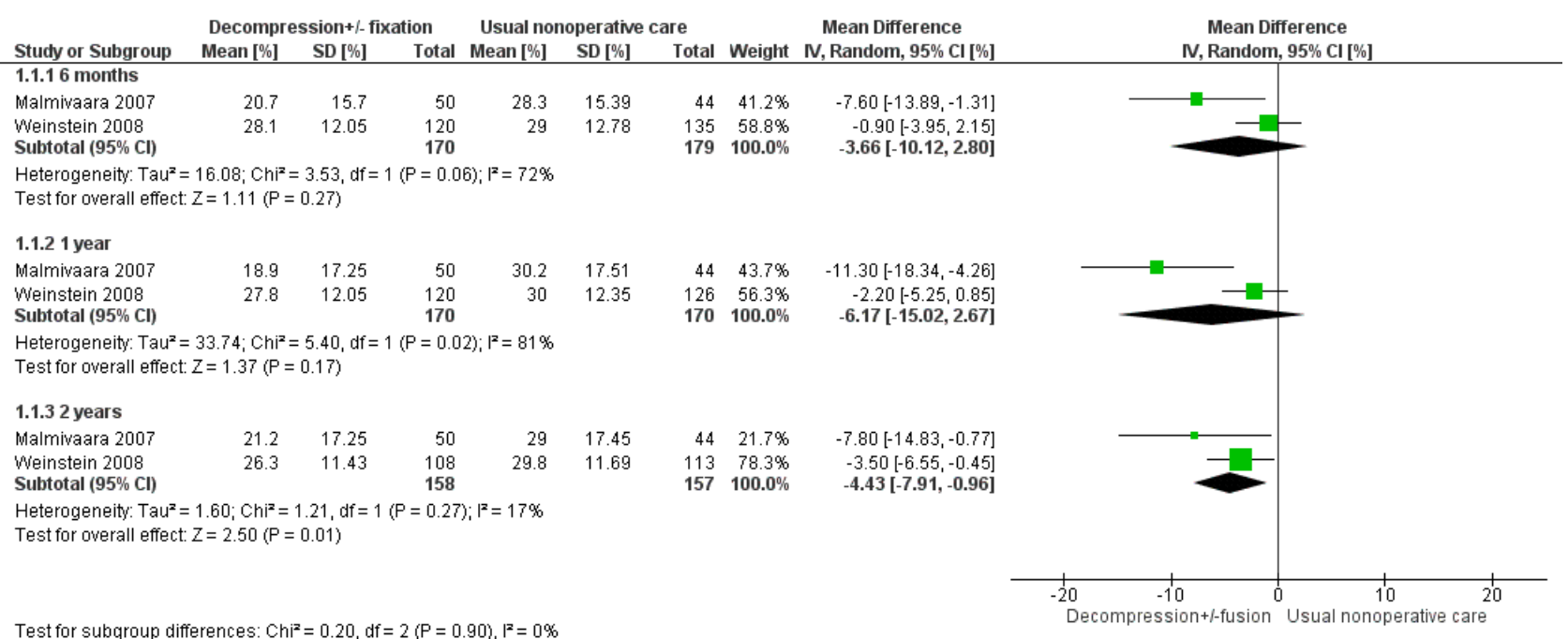

Low-quality evidence from one small study including 31 participants (Amundsen 2000) showed no differences in pain outcomes between decompression and usual conservative care (bracing and exercise) at three months (risk ratio (RR) $1.38,95 \% \mathrm{Cl}$ 0.22 to 8.59 ), at four years (RR $7.50,95 \% \mathrm{Cl} 1.00$ to 56.48 ) and at 10 years (RR 4.09, $95 \% \mathrm{Cl} 0.95$ to 17.58 ) (Figure 5). 
Figure 5. Forest plot of comparison: 1 Decompression \pm fusion versus usual non-operative care for adverse events.

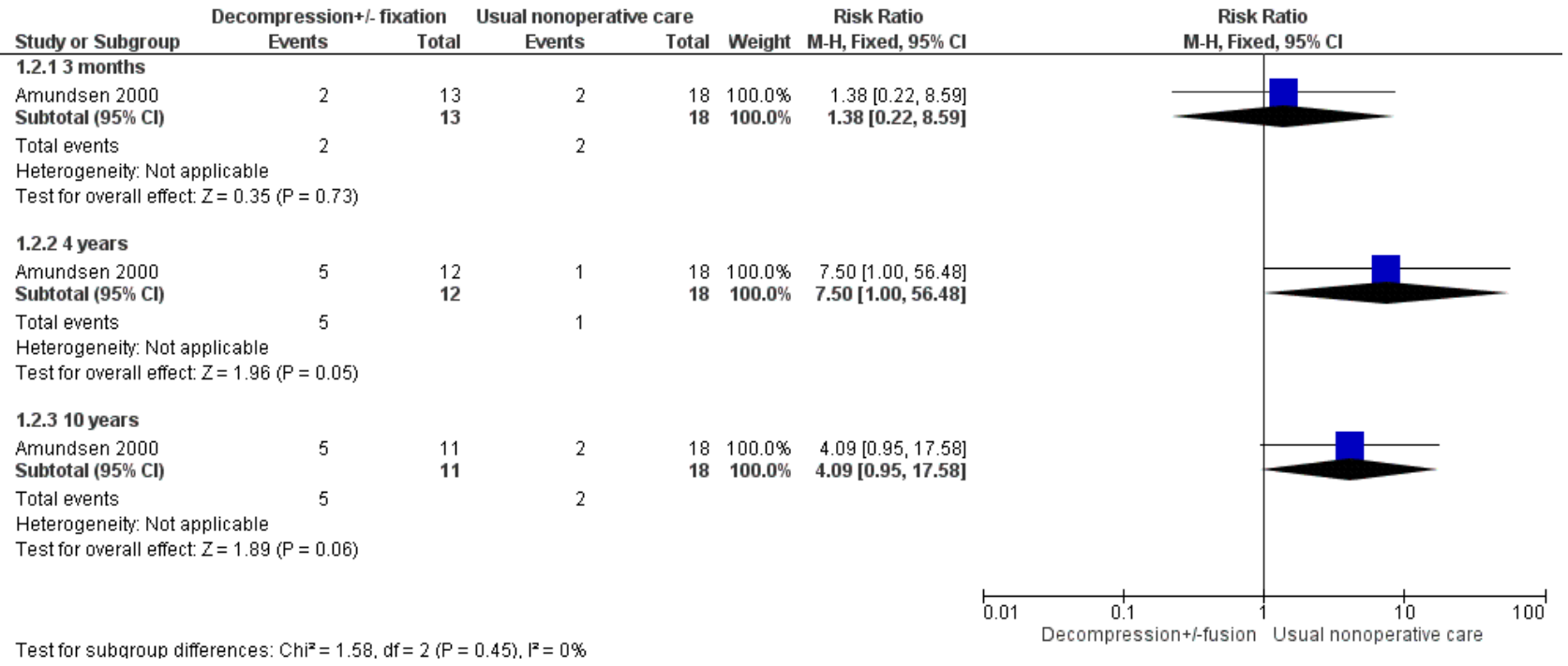

\section{Epidural steroid injection versus decompression with or without fusion}

A single very small study including 38 participants (Brown 2012) found low-quality evidence of no differences at six weeks on the Oswestry Disability Index for individuals treated with mild decompression versus those treated with epidural steroid injections (MD 5.70, 95\% Cl 0.57 to 10.83 ; 38 participants). ZCQ results were better for epidural injection at six weeks (MD -0.60, 95\% $\mathrm{Cl}-0.92$ to -0.28$)$, and VAS improvements were better in the mild decompression group (MD 2.40, 95\% $\mathrm{Cl} 1.92$ to 2.88). At 12 weeks, many cross-overs prevented further analysis.

\section{Usual conservative treatment versus interspinous device}

One trial (Zucherman 2004) compared an interspinous spacer device versus usual conservative care in 191 participants. This trial provided low-quality evidence favouring the interspinous spacer at six weeks, six months and one year for symptom severity and physical function.

\section{Side effects}

Two low-quality studies including 69 participants reported no major side effects (Amundsen 2000; Brown 2012). One study comparing usual conservative treatment with laminectomy with or without fusion reported no deep venous thrombosis, no cardiac problems and no deaths in the surgical procedure group (Amundsen 2000). One study comparing epidural steroid injection versus decompression with or without fusion found no safety differences among groups, with no deaths in either group and no major complications (dural tear, blood loss requiring transfusion, nerve root damage, haematoma, infection and rehospitalisation) (Brown 2012). These two studies reported no minor side effects.

One study including 94 participants compared usual conservative treatment with decompression with or without fusion and reported side effects in 12 out of 50 participants in the surgical group (24\%). Eight were perioperative complications - seven lesions to the dural sac and one misplaced transpedicular screw - and four complications arose after surgery, including one case of neural dysfunction due to a peridural haematoma that led to reoperation (Malmivaara 2007).

Another study including 289 participants reported a 10\% rate of intraoperative complications, mainly dural tear/spinal fluid leak (Weinstein 2008). Postoperatively, a further $10 \%$ rate of complications was detected in the surgical group, including wound haematoma, infection and other unspecified problems. The reoperation rate at four years was $13 \%$. No deaths were reported within the first three months after surgery.

One study including 191 participants compared usual conservative treatment versus an interspinous device and found that $11 \%$ of participants undergoing interspinous spacer implants had side effects, including spinous process fracture, coronary ischaemia, respiratory distress, haematoma and death due to pulmonary oedema (Zucherman 2004).

Investigators reported no side effects for any of the conservative treatments.

\section{DISCUSSION}

Lumbar spinal stenosis (LSS) has a significant impact on mobility, functioning and quality of life. LSS is one of the most commonly treated spinal disorders in older adults, and its prevalence will continue to rise with the aging population. Yet, to date, no clear standard is known for treatment of LSS. As it stands, the boundary between conservative treatment and surgery is not well defined. It is unclear whether either type of treatment is preferable. The objective of this review was to provide a better understanding of the respective benefits of surgical versus nonsurgical treatment. Unfortunately, the studies included in this review were of low quality. Low-quality evidence from three studies shows that decompression and conservative treatment have similar results for disability (Oswestry Disability Index (ODI)) at three, six and 12 months (Amundsen 2000; Malmivaara 2007; Weinstein 2008), and at 24 months, one study reported better results for surgical decompression (Weinstein 2008). One small study comparing steroid injections versus mild decompression found low-quality evidence showing no differences in disability 
(ODI) at six weeks. This same study found that injections were better for physical function (Zurich Claudication Questionnaire (ZCQ)) and worse for pain (visual analogue scale (VAS)) compared with mild decompression at six weeks (Brown 2012). Another single study found low-quality evidence favouring an interspinous device with surgical decompression over conservative treatment at six weeks, six months and one year of follow-up (Zucherman 2004). One study is awaiting classification (Delitto 2015), but the results reported are similar to those described so we don't expect any change in the conclusions.

Investigators reported relevant differences for frequency of side effects, with no side effects reported for the usual conservative care group. Two studies reported no major side effects for decompression with or without fusion, but these studies did not report on minor side effects (Amundsen 2000; Brown 2012). Three studies reported greater detail on side effects. Of these three studies, Weinstein 2008 reported a $10 \%$ rate of perioperative complications, with a further $10 \%$ after surgery; Zucherman 2004 reported a combined rate of $11 \%$ for perioperative and postoperative side effects; and Malmivaara 2007 reported a side effect rate of $24 \%$. Given the overall similarity in efficacy, care providers should consider the risk of side effects when proposing surgical options to patients. A side effect rate of $10 \%$ to $24 \%$ for surgery without clearly superior benefit suggests that clinicians should be very careful when informing patients about possible treatment options, especially given that conservative care options had no associated side effects.

One major limitation in the examination of each of these trials is the lack of a standard conservative treatment method. Studies included different modalities applied in various ways, case by case without a real protocol. It is understandable that conservative treatment approaches are multi-modal, potentially involving different approaches. However, this does not preclude a description of the specific approaches. If we are to understand the effects of conservative treatment, we need to know exactly which type of treatment was applied. Ideally, to properly assess the efficacy of non-surgical treatment approaches, future studies should aim to isolate a specific approach with a clearly defined treatment plan. For example, future studies could compare one type of surgical approach versus a specific aerobic exercise programme, or versus a defined injection protocol. This review demonstrates a clear discrepancy in the description of treatment approaches. A very precise description of surgical procedures was available in all of the included studies, and the description of conservative protocols was poor, or absent, in all studies. This discrepancy could be explained by the fact that the principal investigators in the included studies are surgeons. The need for collaboration between surgical experts and conservative care specialists is clear when future studies are designed to compare surgery versus conservative treatments for LSS.

Another major limitation of available evidence is the lack of standard outcome tools. It is difficult to compare trials when the choice of outcomes is so heterogeneous. Outcome tools most commonly used currently include visual analogue pain scales and various questionnaires related to disability, physical function, symptoms and quality of life. A few trials have employed objective measures, including treadmill tests of walking. Recently the National Institutes on Health (NIH) Pain Consortium charged a Research Task Force to draft standards for research on chronic low back pain (Deyo 2014). This set of standard outcomes could be used in the study of LSS, augmented by LSS-specific outcomes, until a standard for outcomes of LSS has been defined. Additionally, with respect to outcomes, the study of LSS could benefit from the introduction of objective measures of function. Such measures are powerful because they are not subject to the biases associated with self report. Both capacity (how much an individual can do) and performance (what one does in day-to-day life) are important aspects of function that provide us with a greater understanding of patient baseline function and response to treatment. The Self-Paced Walking Test is a validated and reliable measure of walking capacity that was designed specifically for assessment of LSS (Tomkins 2009). Accelerometers serve as a validated means of assessing performance in LSS (Tomkins-Lane 2012b). Future studies of LSS should aim to include objective measures of function that allow unbiased comparison of function between groups.

\section{Summary of main results}

This review analysed five RCTs (10 references) consisting of 643 participants and comparing different surgical procedures and conservative approaches. All five studies applied a decompression modality, varying from standard decompression with or without fusion to less invasive approaches based on interspinous devices. For conservative treatment, researchers applied different modalities, including bracing, physical therapy, epidural steroid injection and other modalities that were not well described.

On the whole, these studies provide conflicting low-quality evidence on the effectiveness of surgery versus conservative treatment for LSS. Study results preclude conclusions regarding whether surgical or non-surgical treatment provides better outcomes for people with LSS.

Surgical groups demonstrated high side effect rates, and conservative treatment groups demonstrated no complications. Further research is needed to compare these approaches. Specifically, studies comparing surgery versus well-defined protocols of non-surgical treatment are warranted.

\section{Overall completeness and applicability of evidence}

The need for additional research on this topic is obvious. However, study of treatments for LSS is hindered by lack of clear diagnostic criteria. It is difficult to combine studies for meta-analyses when definitions of the condition and therefore inclusion criteria are variable. Although major clinical signs, including neurogenic claudication, and flexion-induced symptom relief are considered hallmarks of the condition, no standard for diagnosis is known. When applying evidence from studies of LSS, we must make assumptions about the diagnoses of participants involved in the trials, with awareness that these participant groups likely are not homogenous.

\section{Quality of the evidence}

The overall quality of the evidence was low. The most common issues include lack of blinding, participant cross-over limiting the applicability of ITT and small sample size.

\section{Potential biases in the review process}

Strengths of this review include direct comparison of surgical and non-surgical approaches with all modalities included and 
precise inclusion criteria for patients based on both clinical and radiological data.

\section{Agreements and disagreements with other studies or reviews}

The literature comparing surgical versus non-surgical approaches is inconsistent. A previous systematic review on this topic found more evidence in favour of the surgical approach (Kovacs 2011). However, in contrast to this review, Kovacs et al included a trial on treatment for spondylolisthesis (Weinstein 2007). A recent Cochrane systematic review, based on a previous paper (Ammendolia 2012), focused on non-surgical treatment for lumbar spinal stenosis. Authors of this review reached a conclusion similar to ours: Current evidence for non-operative care is of low and very low quality, prohibiting the generation of recommendations to guide clinical practice (Ammendolia 2013).

\section{AUTHORS' CONCLUSIONS}

\section{Implications for practice}

Current evidence comparing surgical versus non-surgical care for lumbar spinal stenosis is of low quality. For this reason, we cannot conclude whether a surgical or a conservative approach is better for lumbar spinal stenosis, nor can we provide new recommendations to guide clinical practice. Nevertheless, given the high rates of side effects associated with surgery, clinicians should be cautious when proposing surgery for LSS, and patients should be properly informed about the risks. This review also highlights the dearth of high-quality studies comparing surgical versus non-surgical treatment options. In particular, studies with detailed protocols and descriptions of non-surgical treatments are lacking.

\section{Implications for research}

Given the prevalence and economic ramifications of LSS, highquality research comparing surgical versus conservative care is needed. Future studies must take particular care to standardise and adequately describe conservative protocols. Finally, research into treatment for LSS would be much improved by development of standard diagnostic criteria and clinical outcomes.

\section{ACK N O WLEDGEMENTS}

We wish to thank all Cochrane Back Group Editors for their work and continuous help. 


\section{R E F E R E N C E S}

\section{References to studies included in this review}

Amundsen 2000 \{published data only\}

Amundsen T, Weber H, Nordal HJ, Magnaes B, Abdelnoor M, Lilleas F. Lumbar spinal stenosis: conservative or surgical management? A prospective 10-year study. Spine 2000;25(11):1424-35.

\section{Brown 2012 \{published data only\}}

Brown LL. A double-blind, randomized, prospective study of epidural steroid injection vs. the mild procedure in patients with symptomatic lumbar spinal stenosis. Pain Practice 2012;12(5):333-41.

\section{Malmivaara 2007 \{published data only\}}

* Malmivaara A, Slatis P, Heliovaara M, Sainio P, Kinnunen H, Kankare J, et al. Finnish Lumbar Spinal Research Group. Surgical or nonoperative treatment for lumbar spinal stenosis? A randomized controlled trial. Spine 2007;32(1):1-8.

Slätis P, Malmivaara A, Heliövaara M, Sainio P, Herno A, Kankare J, et al. Long-term results of surgery for lumbar spinal stenosis: a randomised controlled trial. European Spine Journal 2011;20(7):1174-81.

\section{Weinstein 2008 \{published data only\}}

Birkmeyer NJ, Weinstein JN, Tosteston AN, Tosteston JD, Skinner JS, Lurie JD. Design of the Spine Patients Outcomes Research Trial (SPORT). Spine 2002;27(12):1361-72.

Radcliff KE, Rihn J, Hilibrand A, Dilorio T, Tosteson T, Lurie JD, et al. Does the duration of symptoms in patients with spinal stenosis and degenerative spondylolisthesis affect outcomes? Analysis of the Spine Outcomes Research Trial. Spine 2011;36(25):2197-210

Weinstein JN, Tosteson TD, Lurie JD, Tosteson A, Blood E, Herkowitz $\mathrm{H}$, et al. Surgical versus nonoperative treatment for lumbar spinal stenosis: four-year results of the Spine Patient Outcomes Research Trial. Spine 2010;35(14):139-48.

* Weinstein JN, Tosteson TD, Lurie JD, Tosteson AN, Blood E, Hanscom B, et al. SPORT Investigators. Surgical versus nonsurgical therapy for lumbar spinal stenosis. New England Journal of Medicine 2008;358(8):794-810.

\section{Zucherman 2004 \{published data only\}}

Zucherman JF, Hsu KY, Hartjen CA, Mehalic TF, Implicito DA, Martin MJ, et al. A multicenter, prospective, randomized trial evaluating the $X$ STOP interspinous process decompression system for the treatment of neurogenic intermittent claudication: two-year follow-up results. Spine 2005;30(12):1351-8.

* Zucherman JF, Hsu KY, Hartjen CA, Mehalic TF, Implicito DA, Martin MJ, et al. A prospective randomized multi-center study for the treatment of lumbar spinal stenosis with the X STOP interspinous implant: 1-year results. European Spine Journal 2004;13(1):22-31.

\section{References to studies excluded from this review}

Athiviraham 2007 \{published data only\}

Athiviraham A, Yen D. Is spinal stenosis better treated surgically or nonsurgically?. Clinical Orthopaedics \& Related Research 2007;458:90-3.

Atlas 1996 \{published data only\}

*Atlas SJ, Deyo RA, Keller RB, Chapin AM, Patrick DL, Long JM, et al. The Maine Lumbar Spine Study, Part III. 1-Year outcomes of surgical and nonsurgical management of lumbar spinal stenosis. Spine (Phila Pa 1976) 1996;21(15):1787-94.

Atlas SJ, Keller RB, Robson D, Deyo RA, Singer DE. Surgical and nonsurgical management of lumbar spinal stenosis: fouryear outcomes from the Maine Lumbar Spine Study. Spine 2000;25(5):556-62.

Atlas SJ, Keller RB, Wu YA, Deyo RA, Singer DE. Long-term outcomes of surgical and nonsurgical management of lumbar spinal stenosis: 8 to 10 year results from the Maine Lumbar Spine Study. Spine 2005;30(8):936-43.

\section{Chang 2005 \{published data only\}}

Chang Y, Singer DE, Wu YA, Keller RB, Atlas SJ. The effect of surgical and nonsurgical treatment on longitudinal outcomes of lumbar spinal stenosis over 10 years. Journal of the American Geriatrics Society 2005;53(5):785-92.

\section{Croft 2012 \{published data only\}}

Croft A. Conservative vs. surgical care of lumbar spinal stenosis. Dynamic Chiropractic 2012;30(5):1-5.

\section{Hurri 1998 \{published data only\}}

Hurri H, Slatis P, Soini J, Tallroth K, Alaranta H, Laine T, et al. Lumbar spinal stenosis: assessment of long-term outcome 12 years after operative and conservative treatment. Journal of Spinal Disorders 1998;11(2):110-5.

Keller 1996 \{published data only\}

Keller RB, Atlas SJ, Singer DE. The Maine Lumbar Spine Study, part I: background and concepts. Spine 1996;21(15):1769-76.

\section{Malmivaara 2007a \{published data only\}}

Malmivaara A, Slatis P, Heliovaara M, Sainio P, Kinnunen H, Kankare J, et al. Surgery reduced pain and disability in lumbar spinal stenosis better than nonoperative treatment. Journal of Bone and Joint Surgery [American] 2007;89(8):1872.

\section{Mariconda 2002 \{published data only\}}

Mariconda M1, Fava R, Gatto A, Longo C, Milano C. Unilateral laminectomy for bilateral decompression of lumbar spinal stenosis: a prospective comparative study with conservatively treated patients. Journal of Spinal Disorders and Techniques 2002;15(1):39-46.

\section{Ohtori 2014 \{published data only\}}

Ohtori S, Yamashita M, Murata Y, Eguchi Y, Aoki Y, Ataka H, et al. Incidence of nocturnal leg cramps in patients with lumbar 
spinal stenosis before and after conservative and surgical treatment. Yonsei Medical Journal 2014;55(3):779-84.

\section{Paker 2005 \{published data only\}}

Paker N, Turkmen C, Bugdayci D, Tekdos D, Erbil M. Comparison of conservative and surgical treatment results in lumbar spinal stenosis. Turkish Neurosurgery 2005;15(4):182-4.

\section{Pearson 2011 \{published data only\}}

Pearson A, Blood E, Lurie J, Abdu W, Sengupta D, Frymoyer JW, et al. Predominant leg pain is associated with better surgical outcomes in degenerative spondylolisthesis and spinal stenosis: results from the Spine Patient Outcomes Research Trial (SPORT). Spine 2011;36(3):219-29.

\section{Tosteson 2011 \{published data only\}}

Tosteson AN, Tosteson TD, Lurie JD, Abdu W, Herkowitz H, Andersson G, et al. Comparative effectiveness evidence from the spine patient outcomes research trial: surgical versus nonoperative care for spinal stenosis, degenerative spondylolisthesis, and intervertebral disc herniation. Spine 2011;36(24):2061-8.

\section{References to studies awaiting assessment}

Delitto 2015 \{published data only\}

Delitto A, Piva SR, Moore CG, Fritz JM, Wisniewski SR, Josbeno DA. Surgery versus nonsurgical treatment of lumbar spinal stenosis: a randomized trial. Annals of Internal Medicine 2015;162(7):465-73.

\section{References to ongoing studies}

Overdevest 2011 \{published data only\}

Overdevest GM, Luijsterburg PA, Brand R, Koes BW, BiermaZienstra SM, Eekhof JA, et al. Design of the Verbiest trial: cost-effectiveness of surgery versus prolonged conservative treatment in patients with lumbar stenosis. BMC Musculoskeletal Disorders 2011;12:57.

\section{Additional references}

\section{Ammendolia 2011}

Ammendolia C, Stuber K, deBruin LK, Furlan AD, Kennedy CA, Rampersaud $Y$, et al. Non-operative treatment for lumbar spinal stenosis with neurogenic claudication: a systematic review. Spine 2011;10:E609-16.

\section{Ammendolia 2012}

Ammendolia C, Stuber K, de Bruin LK, Furlan AD, Kennedy CA, Rampersaud YR, et al. Nonoperative treatment of lumbar spinal stenosis with neurogenic claudication: a systematic review. Spine (Phila Pa 1976) 2012 May 1;37(10):E609-16.

\section{Ammendolia 2013}

Ammendolia C, Stuber KJ, Rok E, Rampersaud R, Kennedy CA, Pennick V, et al. Nonoperative treatment for lumbar spinal stenosis with neurogenic claudication. Cochrane Database of Systematic Reviews 2013 Aug 30;8:CD010712.

\section{Atlas 2006}

Atlas S, Delitto A. Spinal stenosis: surgical versus non surgical treatment. Spinal Stenosis: Surgical versus Non Surgical Treatment. Baltimore, Maryland: Lippincott Williams \& Wilkins, 2006; Vol. 443:198-207.

\section{Benoist 2002}

Benoist M. The natural history of lumbar degenerative spinal stenosis. Joint, Bone, Spine 2002;69(50):450-7.

\section{Binder 2002}

Binder DK, Schmidt MH, Weinstein PR. Lumbar spinal stenosis. Seminars In Neurology 2002;22(2):157-66

\section{Botwin 2007}

Botwin K, Brown LA, Fishman M, Rao S. Fluoroscopically guided caudal epidural steroid injections in degenerative lumbar spine stenosis. Pain Physician 2007;10(4):547-58.

\section{Boutron 2005}

Boutron I, Moher D, Tugwell P, Giraudeau B, Poiraudeau S, Nizard R, et al. A checklist to evaluate a report of a non pharmacological trial (CLEAR NPT) was developed using consensus. Journal of Clinical Epidemiology 2005;58:1233-40.

\section{Carragee 2010}

Carragee EJ. The increasing morbidity of elective spinal stenosis surgery: is it necessary?. JAMA 2010;303(13):1309-10.

\section{Chad 2007}

Chad, DA. Lumbar spinal stenosis. Neurologic Clinics 2007;25(2):407-18.

\section{Ciol 1996}

Ciol MA, Deyo RA, Howell E, Kreif S. An assessment of surgery for spinal stenosis: time trends, geographic variations, complications, and reoperations. Journal of the American Geriatrics Society 1996;44(3):185-90.

\section{Ciricillo 1993}

Ciricillo SF, Weinstein PR. Lumbar spinal stenosis. The Western Journal of Medicine 1993;158:171-7.

\section{Deyo 2006}

Deyo RA, Mirza SK. Trends and variations in the use of spine surgery. Clinical Orthopaedics and Related Research 2006;443:139-46.

\section{Deyo 2010}

Deyo RA, Mirza SK, Martin BI. Trends, major medical complications, and charges associated with surgery for lumbar spinal stenosis in older adults. JAMA 2010;303:1259-65.

\section{Deyo 2011}

Deyo RA, Martin BI, Kreuter W, Jarvik JG, Angier H, Mirza SK. Revision surgery following operations for lumbar stenosis. The Journal of Bone and Joint Surgery [American] 2011;93(21):1979-86. 


\section{Deyo 2014}

Deyo RA, Dworkin SF, Amtmann D, Andersson G, Borenstein D, Carragee E, et al. Focus article: report of the NIH Task Force on Research Standards for Chronic Low Back Pain. European Spine Journal 2014;23(10):2028-45.

\section{Duffy 2014}

Duffy S, Misso K, Noake C, Ross J, Stirk L. Supplementary searches of PubMed to improve currency of MEDLINE and MEDLINE In-Process searches via OvidSP. Kleijnen Systematic Reviews Ltd, York. Poster presented at the UK InterTASC Information Specialists' Sub-Group (ISSG) Workshop; 9 July 2014; Exeter: UK (2014) (accessed 6.8.14). https://medicine.exeter.ac.uk/media/ universityofexeter/medicalschool/research/pentag/documents/ Steven_Duffy_ISSG_Exeter_2014_poster_1.pdf.

\section{Fanuele 2000}

Fanuele JC, Birkmeyer NJ, Abdu MD, Tosteson TD, Weinstein JN. The impact of spinal problems on the health status of patients: have we underestimated the effect?. Spine 2000;25(12):1509-14.

\section{Furlan 2009}

Furlan AD, Pennick V, Bombardier C, van Tulder M, Editorial BCBRG. 2009 Updated method guidelines for systematic reviews in the Cochrane Back Review Group. Spine 2009;34(18):1929-41.

\section{Haig 2006}

Haig AJ, Tong HC, Yamakawa KS, Quint DJ, Hoff JT, Chiodo A, et al. Spinal stenosis, back pain, or no symptoms at all? A masked study comparing radiologic and electrodiagnostic diagnoses to the clinical impression. Archives of Physical Medicine and Rehabilitation 2006;7(7):897-903.

\section{Haig 2010}

Haig AJ, Tomkins CC. Diagnosis and management of lumbar spinal stenosis. JAMA 2010;303(1):71-2.

\section{Higgins 2011}

Higgins JPT, Green S (editors). Cochrane Handbook for Systematic Reviews of Interventions Version 5.1.0 [updated March 2011]. The Cochrane Collaboration, 2011. www.cochranehandbook.org.

\section{Iversen 2001}

Iversen MD, Katz JN. Examination findings and self-reported walking capacity in patients with lumbar spinal stenosis. Physical Therapy 2001;81(7):1296-306.

\section{Johnsson 1987}

Johnsson KE, Rosén I, Udén A. Neurophysiologic investigation of patients with spinal stenosis. Spine 1987;12(5):483-7.

\section{Kovacs 2011}

Kovacs F, Urrútia G, Alarcón JD. Surgery versus conservative treatment for symptomatic lumbar spinal stenosis: a systematic review of randomized controlled trials. Spine 2011;36(20):E1335-51.

\section{Lurie 2003}

Lurie JD, Birkmeyer NJ, Weinstein JN. Rates of advanced spinal imaging and spine surgery. Spine 2003;28(6):616-20.

\section{Negrini 2006}

Negrini S, Giovannoni S, Minozzi S, Barneschi G, Bonaiuti D, Bussotti A, et al. Diagnostic therapeutic flow-charts for low back pain patients: the Italian clinical guidelines. Europa Medicophysica 2006;42(2):151-70.

\section{Negrini 2010}

Negrini S, Zaina F, Romano M, Atanasio S, Fusco C, Trevisan C. Rehabilitation of lumbar spine disorders: an evidencebased clinical practice approach. In: Frontera WR, Delisa JA, Gans BM, Walsh NE, Robinson LR editor(s). DeLisa's Physical \& Rehabilitation - Principles and Practice. 5th Edition. Baltimore, Maryland: Lippincott Williams \& Wilkins, 2010:837-82.

\section{Porter 1996}

Porter RW. Spinal stenosis and neurogenic claudication. Spine 1996;21(17):2046-52.

\section{Postacchini 1999}

Postacchini F. Surgical management of lumbar spinal stenosis. Spine 1999;15(24):1043-7.

\section{Sobottke 2010}

Sobottke R, Röllinghoff M, Siewe J, Schlegel U, Yagdiran A, Spangenberg M, et al. Clinical outcomes and quality of life 1 year after open microsurgical decompression or implantation of an interspinous stand-alone spacer. Minimally Invasive Neurosurgery 2010;53(4):179-83.

\section{Stucki 1995}

Stucki G, Liang MH, Fossel AH, Katz JN. Relative responsiveness of condition-specific and generic health status measures in degenerative lumbar spinal stenosis. Journal of Clinical Epidemiology 1995;48(11):1369-78.

\section{Taylor 1994}

Taylor VM, Deyo RA, Cherkin DC, Kreuter W. Low back pain hospitalization. Recent United States trends and regional variations. Spine 1994;19(11):1207-12; discussion 13.

\section{Tomkins 2009}

Tomkins CC, Battié MC, Rogers T, Jiang H, Petersen S. A criterion measure of walking capacity in lumbar spinal stenosis and its comparison with a treadmill protocol. Spine (Phila Pa 1976) 2009;34(22):2444-9.

\section{Tomkins 2010}

Tomkins CC, Dimoff KH, Forman HS, Gordon ES, McPhail J, Wong JR, et al. Physical therapy treatment options for lumbar spinal stenosis. Journal of Back and Musculoskeletal Rehabilitation 2010;23(1):31-7.

\section{Tomkins-Lane 2012}

Tomkins-Lane CC, Holz SC, Yamakawa KS, Phalke VV, Quint DJ, Miner J, et al. Predictors of walking performance and walking capacity in people with lumbar spinal stenosis, low back pain, 
and asymptomatic controls. Archives of Physical Medicine and Rehabilitation 2012;93(4):647-53.

\section{Tomkins-Lane 2012b}

Tomkins-Lane CC, Haig AJ. A review of activity monitors as a new technology for objectifying function in lumbar spinal stenosis. Journal of Back and Musculoskeletal Rehabilitation 2012;25(3):177-85.

\section{Tomkins-Lane 2015}

Tomkins-Lane CC, Lafave LM, Parnell JA, Rempel J, Moriartey S, Andreas $\mathrm{Y}$, et al. The spinal stenosis pedometer and nutrition lifestyle intervention (SSPANLI): development and pilot. The Spine Journal 2015;15(4):577-86.

\section{van Tulder 2003}

van Tulder M, Furlan A, Bombardier C, Bouter L, Editorial Board Cochrane Back Review Group. Updated method guidelines for systemic reviews in the Cochrane Collaboration Back Review Group. Spine 2003;28(12):1290-9.

\section{Watters 2008}

Watters WC, Baisden J, Gilbert TJ, Kreiner S, Resnick DK, Bono CM, et al. Degenerative lumbar spinal stenosis: an evidence-based clinical guideline for the diagnosis and treatment of degenerative lumbar spinal stenosis. The Spine Journal 2008;8(2):305-10.

\section{Weinstein 2007}

Weinstein JN, Lurie JD, Tosteson TD, Hanscom B, Tosteson AN, Blood EA, et al. Surgical versus non surgical treatment for lumbar degenerative spondylolisthesis. New England Journal of Medicine 2007;356(22):2257-70.

\section{Whitman 2003}

Whitman JM, Flynn TW, Fritz JM. Nonsurgical management of patients with lumbar spinal stenosis: a literature review and a case series of three patients managed with physical therapy. Physical Medicine and Rehabilitation Clinics of North America 2003;14:77-101.

* Indicates the major publication for the study

\section{CHARACTERISTICS OF STUDIES}

Characteristics of included studies [ordered by study ID]

Amundsen 2000

\begin{tabular}{ll}
\hline Methods & Randomised controlled trial \\
\hline Participants & 100 patients with symptomatic lumbar spinal stenosis, 54 men and 46 women whose median age was \\
& 59 years (range 16 to 77 years). From these patients, a group $\mathrm{S}(\mathrm{n}=19)$ was selected for surgical treat- \\
ment because of the severity of their symptoms, and a group $\mathrm{C}(\mathrm{n}=50)$, with milder pain, was selected \\
for conservative treatment. Remaining patients, group $\mathrm{R}(\mathrm{n}=31)$, whose severity of pain left the physi- \\
cian in doubt concerning which treatment to recommend, was randomly assigned to surgical treat- \\
ment (group RS ( $\mathrm{n}=13$ ) or conservative treatment (group RC ( $\mathrm{n}=18)$ \\
Inclusion criteria: sciatic pain in the leg(s), with or without pain in the back, together with radiological \\
signs of stenosis and compression of clinically afflicted nerve root(s)
\end{tabular}
signs of stenosis and compression of clinically afflicted nerve root(s)

Exclusion criteria: bulging or herniated disc, spondylolysis, coxarthrosis, gonarthrosis, arterial insufficiency in the legs, polyneuropathy, concomitant serious disease, previous surgery on the back

Interventions Surgical procedure: standardised for the purpose of nerve decompression by partial or total laminectomy, medial facetectomy, discectomy and/or removal of osteophytes from the vertebral margins or facet joints. Hypertropic ligamenta flava were removed if necessary. No fusions were performed

Conservative treatment: fitted with an orthosis and transferred to the rehabilitation department for 1 month. No regular physiotherapy was given, except for instruction and "back school"

\section{Outcomes}

Outcomes: Visual Analogue Pain Scale, Verbal Rating Scale, Subjective Change (better, worse or unchanged), Work Status, Subjective Physician Rating (excellent, fair, unchanged, worse)

Time points: 6 months, 12 months, 4 years, 10 years

\section{Notes}

\section{Risk of bias}

Bias Authors' judgement Support for judgement


Amundsen 2000 (Continued)

Random sequence genera- Unclear risk Block randomisation using tables of random numbers tion (selection bias)

\begin{tabular}{lll}
\hline $\begin{array}{l}\text { Allocation concealment } \\
\text { (selection bias) }\end{array}$ & Unclear risk
\end{tabular}

Blinding (performance $\quad$ High risk Blinding of participants not possible for the types of interventions compared
bias and detection bias)
All outcomes

\begin{tabular}{lll}
\hline $\begin{array}{l}\text { Incomplete outcome data } \\
\text { (attrition bias) } \\
\text { All outcomes }\end{array}$ & High risk & Only completers included \\
\hline $\begin{array}{l}\text { Selective reporting (re- } \\
\text { porting bias) }\end{array}$ & High risk & Data not fully reported \\
\hline $\begin{array}{l}\text { Group similarity at base- } \\
\text { line (selection bias) }\end{array}$ & Low risk & Similar characteristics between groups at baseline \\
\hline $\begin{array}{l}\text { Co-interventions (perfor- } \\
\text { mance bias) }\end{array}$ & Low risk & No co-intervention unbalance \\
\hline $\begin{array}{l}\text { Compliance (performance } \\
\text { bias) }\end{array}$ & High risk & Compliance not monitored for conservative treatment group \\
\hline $\begin{array}{l}\text { Intention-to-treat-analysis } \\
\text { Timing of outcome assess- } \\
\text { ments (detection bias) }\end{array}$ & Low risk & ITT performed \\
\hline \begin{tabular}{l} 
Other bias \\
\hline
\end{tabular} & High risk & Similar timing for both groups \\
\hline
\end{tabular}

Brown 2012

\begin{tabular}{ll}
\hline Methods & Double-blind randomised prospective study \\
\hline Participants & 38 participants were randomly assigned to 2 treatment groups, with 21 included in the mild group and \\
17 in the ESI group & \\
Inclusion criteria: patients with symptomatic LSS with painful lower limb neurogenic claudication and \\
hypertrophic ligamentum flavum as a contributing factor. All patients were at least 18 years of age, had \\
previously failed conservative therapy and presented with an Oswestry Disability Index (ODI) score > \\
20. Radiological evidence showed LSS (L3-L5), ligamentum flavum $>2.5$ mm confirmed by preopera- \\
tive MRI or CT, central canal cross-sectional area $£ 100$ mm 2 and anterior listhesis confirmed at $£ 5.0$ \\
mm for all patients. All were able to walk at least 10 feet unaided before they were limited by pain \\
Exclusion criteria: prior surgery at the intended treatment level or previous treatment with epidural \\
steroids. History of recent spinal fracture, disabling back or leg pain from causes other than LSS, fixed \\
spondylolisthesis \\
> grade 1 , disc protrusion or osteophyte formationor excessive facet hypertrophy. Patients with bleed- \\
ing disorders, current use of anticoagulants or wound healing pathologies deemed to compromise out- \\
comes, such as diabetes, cancer, and severe COPD; and those who had used ASA or NSAID within 5 days \\
of treatment were not eligible
\end{tabular}


Brown 2012 (Continued)

Finally, patients who were pregnant or breastfeeding, unable to lie prone for any reason with anaesthesia support, unable to give informed consent, on Workman's Compensation or considering litigation associated with back pain were excluded

Interventions

Conservative treatment (epidural steroid treatment): Participants received $80 \mathrm{mg}$ of triamcinolone acetate ( $40 \mathrm{mg}$ in diabetic patients) mixed with $6 \mathrm{~mL}$ of preservative-free saline injected in divided doses at treated levels. Injections were delivered at the level of pathology with fluoroscopy and radiographic contrast used to document accurate placement of the steroid into the epidural space. In addition, skin anaesthesia and a small incision, followed by trocar placement under fluoroscopy as with the mild procedure, were performed. No bone or tissue was removed, and thus, no decompression procedure was performed. Wounds were dressed and cared for postoperatively identically to those in the mild treatment group. Individuals randomly assigned to mild received no steroid

Surgical treatment: mild lumbar decompression procedure performed. Mild devices are designed to access the interlaminar space from the posterior lumbar spine, enabling removal of small portions of lamina and hypertrophic ligamentum flavum, thereby achieving lumbar decompression. Initially, the mild patient is placed in the prone position for posterior spinal access. Frequently, a bolster is used to open the spinal anatomy for treatment. An epidurogram is performed at the beginning of the procedure for the purpose of identifying the border of the dural and epidural space relative to the ligamentum flavum and interlaminar space. On the basis of these visual landmarks, the mild trocar and portal system is advanced under manual control and is positioned under fluoroscopic guidance. The trocar is then removed, and the 6-gauge mild portal is secured in place, with the portal stabiliser becoming the percutaneous working port for the procedure. The bone sculpter rongeur is advanced through the secured portal to the laminar bone surface. This device is used to precisely cut and remove very small pieces of bone until access to the ligamentous tissue has been created. The mild tissue sculpter is then placed through the portal and through the laminotomy to excise portions of hypertrophic ligamentum flavum. Progressive tissue cuts are performed to the inferior edge and under the ventral surface of the lamina, under fluoroscopic guidance. The amount of decompression is assessed through visual observation of epidurogram contrast flow, as the flow becomes thicker and straighter. Once the procedure is complete, the mild portal and stabiliser assembly is removed. No implants are left behind, and the site is closed with a sterile adhesive strip. The mild procedure is usually performed with only light sedation and local anaesthetic

\section{Outcomes}

Outcomes: Visual Analogue Pain Scale, Oswestry Disability Index, Zurich Claudication Questionnaire

Time points: 6 weeks, 12 weeks

Notes

\section{Risk of bias}

\begin{tabular}{lll}
\hline Bias & Authors' judgement & Support for judgement \\
\hline $\begin{array}{l}\text { Random sequence genera- } \\
\text { tion (selection bias) }\end{array}$ & Low risk & Randomisation determined by the independent statistician in blocks of 4 \\
\hline $\begin{array}{l}\text { Allocation concealment } \\
\text { (selection bias) }\end{array}$ & Low risk & $\begin{array}{l}\text { Neither enrolling physician nor participant was aware of the participant's ulti- } \\
\text { mate treatment group }\end{array}$ \\
\hline $\begin{array}{l}\text { Blinding (performance } \\
\text { bias and detection bias) } \\
\text { All outcomes }\end{array}$ & Low risk & $\begin{array}{l}\text { Both groups received skin anaesthesia and a small incision. Wounds were } \\
\text { dressed and cared for identically postoperatively. Participants and raters were } \\
\text { blinded }\end{array}$ \\
\hline $\begin{array}{l}\text { Incomplete outcome data } \\
\text { (attrition bias) } \\
\text { All outcomes }\end{array}$ & Low risk & All outcomes reported \\
\hline $\begin{array}{l}\text { Selective reporting (re- } \\
\text { porting bias) }\end{array}$ & Low risk & All outcomes reported \\
\hline
\end{tabular}


Brown 2012 (Continued)

Group similarity at base- Low risk Similar characteristics between groups at baseline line (selection bias)

Co-interventions (perfor- Low risk No co-intervention unbalance
mance bias)

\begin{tabular}{|c|c|c|}
\hline $\begin{array}{l}\text { Compliance (performance } \\
\text { bias) }\end{array}$ & Low risk & Similar compliance for both groups \\
\hline Intention-to-treat-analysis & Unclear risk & ITT performed \\
\hline $\begin{array}{l}\text { Timing of outcome assess- } \\
\text { ments (detection bias) }\end{array}$ & Unclear risk & Similar timing for both groups \\
\hline Other bias & Unclear risk & No further details available \\
\hline
\end{tabular}

Malmivaara 2007

\begin{tabular}{ll}
\hline Methods & Randomised controlled trial \\
\hline Participants & $\begin{array}{l}94 \text { participants were randomly assigned to a surgical or non-operative treatment group: } 50 \text { (age } 62 \pm 9 \text { ) } \\
\text { and } 44 \text { participants }(63 \pm 9), \text { respectively }\end{array}$
\end{tabular}

Inclusion criteria: back pain radiation to lower limbs or buttocks; fatigue or loss of sensation in the lower limbs aggravated by walking; persistent pain without progressive neurological dysfunction; imaging techniques: spinal canal narrowing, sagittal diameter of the dural sac $<10 \mathrm{~mm}^{2}$ or planimetrically assessed cross-sectional dural area $<75 \mathrm{~mm}$; duration of symptoms and signs $>6$ months; clinical signs and symptoms corresponding to segmental radiographic level of stenosis; severity of the disease justifying surgical or non-operative treatment

Exclusion criteria: severe LSS with intractable pain and progressive neurological dysfunction, suggesting forthcoming surgical treatment; mild LSS, characterised by radiographic narrowing of the lumbar spinal canal, but clinical signs and symptoms feeble enough to exclude surgical intervention; spinal stenosis not caused by degeneration, e.g. congenital spinal stenosis; spondylolysis and spondylolytic spondylolisthesis; previous back operation due to spinal stenosis or instability; lumbar herniated disc diagnosed during last 12 months; another specific spinal disorder, e.g. ankylosing spondylitis, neoplasm or metabolic disease; intermittent claudication due to atherosclerosis; severe osteoarthrosis or arthritis causing dysfunction of the lower limbs; neurological disease causing impaired function of the lower limbs, including diabetic neuropathy; psychiatric disorders; alcoholism

Interventions

Surgical group: segmental decompression and an undercutting facetectomy of the affected area performed. Presence or risk of lumbar instability was, at the surgeon's discretion, treated by fusion of the lumbar spine, if necessary, augmented by transpedicular instrumentation. Treated individuals also received a brochure and instructions about pain relief and management

Conservative treatment: non-steroidal anti-inflammatory drugs prescribed when indicated and individuals referred to physiotherapists. Participants were seen 1 to 3 times by a physiotherapist, in addition to the standard visit at each follow-up occasion. The physiotherapist gave all participants a printed brochure describing the nature of spinal stenosis, characteristic symptoms and signs of the disease and the principles of activation and physical training

Participants were encouraged to use their back in a normal way. Pain-relieving body postures were taught to participants as well as basic ergonomics related to lifting and carrying. Individually structured programmes included trunk muscle endurance and stretching-type exercises. Additional individual physiotherapy consisting of passive treatment methods (such as ultrasound and transcutaneous nerve stimulation) and/or active back exercises was prescribed by a physiatrist to $24 \%$ (10 participants) of the non-operative study group 
Malmivaara 2007 (Continued)

Outcomes
Outcomes: 11-point numerical pain scale for leg and back, Oswestry Disability Index, walking ability (distance without a break measured by treadmill), General Health Status (very good, quite good, average, quite poor, very poor)

Time points: 6,12 and 24 months

\section{Notes}

\section{Risk of bias}

\begin{tabular}{|c|c|c|}
\hline Bias & Authors' judgement & Support for judgement \\
\hline $\begin{array}{l}\text { Random sequence genera- } \\
\text { tion (selection bias) }\end{array}$ & Low risk & Computer-generated random blocks of variable size separate for each hospital \\
\hline $\begin{array}{l}\text { Allocation concealment } \\
\text { (selection bias) }\end{array}$ & Unclear risk & Details not provided \\
\hline $\begin{array}{l}\text { Blinding (performance } \\
\text { bias and detection bias) } \\
\text { All outcomes }\end{array}$ & High risk & Blinding of participants not possible for the types of interventions compared \\
\hline $\begin{array}{l}\text { Incomplete outcome data } \\
\text { (attrition bias) } \\
\text { All outcomes }\end{array}$ & High risk & Analysis performed only for completers \\
\hline $\begin{array}{l}\text { Selective reporting (re- } \\
\text { porting bias) }\end{array}$ & Low risk & All outcomes reported \\
\hline $\begin{array}{l}\text { Group similarity at base- } \\
\text { line (selection bias) }\end{array}$ & Unclear risk & Similar characteristics between groups at baseline \\
\hline $\begin{array}{l}\text { Co-interventions (perfor- } \\
\text { mance bias) }\end{array}$ & High risk & $\begin{array}{l}\text { Co-intervention unbalanced in control groups as } 24 \% \text { performed supplemen- } \\
\text { tary exercise }\end{array}$ \\
\hline $\begin{array}{l}\text { Compliance (performance } \\
\text { bias) }\end{array}$ & High risk & Compliance not monitored in the control group \\
\hline Intention-to-treat-analysis & Low risk & ITT performed \\
\hline $\begin{array}{l}\text { Timing of outcome assess- } \\
\text { ments (detection bias) }\end{array}$ & Low risk & Similar timing of outcome assessments for both groups \\
\hline Other bias & Unclear risk & Insufficient details given \\
\hline
\end{tabular}

\section{Weinstein 2008}

\begin{tabular}{|c|c|}
\hline Methods & Multi-centre randomised controlled trial and prospective observational study \\
\hline Participants & $\begin{array}{l}289 \text { participants with a history of neurogenic claudication or radicular leg symptoms } \geq 12 \text { weeks and } \\
\text { confirmatory cross-sectional imaging showing lumbar spinal stenosis at } \geq 1 \text { level were included in the } \\
\text { randomly assigned arm. Mean age } 65.5 \pm 10.5 \text {, females } 38 \% \text {. Patients with degenerative spondylolisthe- } \\
\text { sis on instability were excluded. } 138 \text { participants were assigned to the surgical group, and } 151 \text { to the } \\
\text { non-surgical group }\end{array}$ \\
\hline
\end{tabular}


Weinstein 2008 (Continued)

Interventions
The protocol surgery was standard posterior decompressive laminectomy. The non-surgical protocol consisted of "usual care", which was recommended to include at least active physical therapy, education or counselling with home exercise instruction and administration of non-steroidal anti-inflammatory drugs, if tolerated

\section{Outcomes}

Outcomes: SF-36, Oswestry Disability Index (MODEMS version), Low Back Pain Bothersomeness Scale, Leg Pain Bothersomeness Scale, Stenosis Bothersomeness Index, Self-Reported Satisfaction

Time points: 6 weeks, 3 months, 6 months, and 1, 2 and 4 years

\section{Notes}

\section{Risk of bias}

\begin{tabular}{|c|c|c|}
\hline Bias & Authors' judgement & Support for judgement \\
\hline $\begin{array}{l}\text { Random sequence genera- } \\
\text { tion (selection bias) }\end{array}$ & Low risk & Block randomisation with variable clock size stratified according to centre \\
\hline $\begin{array}{l}\text { Allocation concealment } \\
\text { (selection bias) }\end{array}$ & Unclear risk & Details not provided \\
\hline $\begin{array}{l}\text { Blinding (performance } \\
\text { bias and detection bias) } \\
\text { All outcomes }\end{array}$ & High risk & $\begin{array}{l}\text { Blinding of participants not possible because of the types of interventions } \\
\text { compared }\end{array}$ \\
\hline $\begin{array}{l}\text { Incomplete outcome data } \\
\text { (attrition bias) } \\
\text { All outcomes }\end{array}$ & High risk & Large number of cross-overs made ITT impossible after the first phase \\
\hline $\begin{array}{l}\text { Selective reporting (re- } \\
\text { porting bias) }\end{array}$ & Low risk & All outcomes reported \\
\hline $\begin{array}{l}\text { Group similarity at base- } \\
\text { line (selection bias) }\end{array}$ & High risk & Worst pain, function and disability at baseline in surgery group \\
\hline $\begin{array}{l}\text { Co-interventions (perfor- } \\
\text { mance bias) }\end{array}$ & Unclear risk & No co-intervention unbalance \\
\hline $\begin{array}{l}\text { Compliance (performance } \\
\text { bias) }\end{array}$ & High risk & Compliance not monitored in the control group \\
\hline Intention-to-treat-analysis & High risk & $\begin{array}{l}\text { Large number of cross-overs made ITT impossible after first phase data from } \\
\text { the randomly assigned arm were mixed with those from the observational } \\
\text { arm. Data from the randomly assigned arm were presented separately only for } \\
\text { the as-treated protocol }\end{array}$ \\
\hline $\begin{array}{l}\text { Timing of outcome assess- } \\
\text { ments (detection bias) }\end{array}$ & Low risk & Similar for both groups \\
\hline Other bias & Unclear risk & Insufficient details given \\
\hline
\end{tabular}

Methods Multi-centre randomised clinical trial


Zucherman 2004 (Continued)

Participants
Nine centres randomly assigned 200 participants between May of 2000 and July of 2001, in a prospective, controlled trial. Of 200 participants enrolled in this study, 191 were treated: 100 in the X STOP group and 91 in the conservative group. Most of the 9 patients from conservative group who withdrew from the study before receiving their initial epidural injection entered the study with the hope of being randomly assigned to the $\mathrm{X}$ STOP group

Inclusion criteria: $\geq 50$ years of age with leg, buttock or groin pain, with or without back pain, that could be relieved during flexion; able to sit for 50 minutes without pain and to walk 50 or more feet; completed $\geq 6$ months of non-operative therapy. Stenosis was confirmed by CT or MRI scans at 1 or 2 levels

Primary exclusion criteria: fixed motor deficit, cauda equina syndrome, significant lumbar instability, previous lumbar surgery, significant peripheral neuropathy or acute denervation secondary

to radiculopathy, scoliotic Cobb angle $>25^{\circ}$, spondylolisthesis $>$ grade 1.0 (on a scale of 1 to 4 ) at the affected level, sustained pathological fractures or severe osteoporosis, obesity, active infection or systemic disease, Paget's disease or metastasis to the vertebrae, steroid use for longer than 1 month within 12 months preceding the start of the study

Interventions

Participants enrolled in the X STOP group underwent surgery for implantation of the interspinous implant. Those randomly assigned to the conservative group received $\geq 1$ epidural steroid injection and could receive non-steroidal anti-inflammatory drugs, analgesics and physical therapy. Physical therapy consisted of back school and modalities such as ice packs, heat packs, massage, stabilisation exercises and pool therapy. Braces, such as abdominal binders and corsets, were permitted, but body jackets and chair-back braces were not allowed

Outcomes Outcomes: SF-36, Zurich Claudication Questionnaire (ZCQ), Oswestry Disabilty Index, Worker's Compensation Claim, radiographic changes

Time points: 6 weeks, 6 months, 1 year

\section{Notes}

\section{Risk of bias}

\begin{tabular}{lll}
\hline Bias & Authors' judgement & Support for judgement \\
\hline $\begin{array}{l}\text { Random sequence genera- } \\
\text { tion (selection bias) }\end{array}$ & Unclear risk & Block randomisation by surgical centre \\
\hline $\begin{array}{l}\text { Allocation concealment } \\
\text { (selection bias) }\end{array}$ & Low risk & $\begin{array}{l}\text { After baseline examination and questionnaires were completed, treating } \\
\text { physician phoned the central office, gave participant identification data and } \\
\text { received treatment allocation }\end{array}$ \\
\hline
\end{tabular}

Blinding (performance

bias and detection bias)

All outcomes
High risk

Blinding of participants not possible for the types of interventions compared

Incomplete outcome data High risk $\quad$ Only data from completers used
(attrition bias)

All outcomes

Selective reporting (re- Low risk All outcomes reported
porting bias)

\begin{tabular}{l}
$\begin{array}{l}\text { Group similarity at base- } \\
\text { line (selection bias) }\end{array}$ \\
\hline
\end{tabular}
Co-interventions (perfor-
High risk
Co-interventions not standardised and not properly described
mance bias) 
Zucherman 2004 (Continued)

Compliance (performance High risk Compliance not monitored for the control group bias)

\begin{tabular}{lll}
\hline Intention-to-treat-analysis & Unclear risk & Not described \\
\hline $\begin{array}{l}\text { Timing of outcome assess- } \\
\text { ments (detection bias) }\end{array}$ & Unclear risk & Similar timing for both groups \\
\hline Other bias & Unclear risk & Not clear \\
\hline
\end{tabular}

Abbreviations:

ASA: acetylsalicylic acid.

COPD: chronic obstructive pulmonary disease.

$\mathrm{CT}$ : computed tomography.

ESI: epidural steroid injections

ITT: intention-to-treat.

LSS: lumbar spinal stenosis.

MRI: magnetic resonance imaging.

ODI: Oswestry Disability Index.

SF-36: Short Form 36.

Characteristics of excluded studies [ordered by study ID]

\begin{tabular}{|c|c|}
\hline Study & Reason for exclusion \\
\hline Athiviraham 2007 & Not randomly assigned \\
\hline Atlas 1996 & Not randomly assigned \\
\hline Chang 2005 & Not randomly assigned \\
\hline Croft 2012 & Review, not original data \\
\hline Hurri 1998 & Not randomly assigned \\
\hline Keller 1996 & Protocol of a cohort study \\
\hline Malmivaara 2007a & Commentary, no data \\
\hline Mariconda 2002 & Not randomly assigned \\
\hline Ohtori 2014 & Not randomly assigned \\
\hline Paker 2005 & Not randomly assigned \\
\hline Pearson 2011 & Mixed population including spondylolisthesis \\
\hline Tosteson 2011 & $\begin{array}{l}\text { Cost-effectiveness analysis of mixed population including spondylolisthesis and disc hernia- } \\
\text { tion }\end{array}$ \\
\hline
\end{tabular}

Characteristics of studies awaiting assessment [ordered by study ID] 
Delitto 2015

\begin{tabular}{ll}
\hline Methods & Multi-site randomised controlled trial \\
\hline Participants & $\begin{array}{l}169 \text { participants with lumbar spinal stenosis (LSS) } 50 \text { years of age or older. } 87 \text { underwent surgery } \\
\text { and } 82 \text { physical therapy (PT) }\end{array}$ \\
\hline Interventions & Surgical decompression vs physical therapy \\
\hline Outcomes & $\begin{array}{l}\text { Mean improvement in physical function for surgery and PT groups was } 22.4(95 \% \text { confidence inter- } \\
\text { val (CI) } 16.9 \text { to } 27.9) \text { and } 19.2(95 \% \text { CI } 13.6 \text { to } 24.8) \text {, respectively Intention-to-treat analyses revealed } \\
\text { no differences between groups (24-month difference } 0.9,95 \% \text { Cl }-7.9 \text { to } 9.6) \text {. Sensitivity analyses } \\
\text { using causal-effects methods to account for the high proportion of cross-overs from PT to surgery } \\
\text { (57\%) showed no significant differences in physical function between groups }\end{array}$
\end{tabular}

Notes

Characteristics of ongoing studies [ordered by study ID]

Overdevest 2011

\begin{tabular}{|c|c|}
\hline Trial name or title & Verbiest \\
\hline Methods & Multi-centre randomised controlled trial \\
\hline Participants & $\begin{array}{l}\text { Patients ( }>50 \text { years of age) with } \geq 3 \text { months of complaints of neurogenic intermittent claudication } \\
\text { and considering surgical treatment are eligible for inclusion }\end{array}$ \\
\hline Interventions & Prolonged conservative treatment vs surgery \\
\hline Outcomes & $\begin{array}{l}\text { Primary } \\
\text { - Zurich Claudication Questionnaire } \\
\text { - Shuttle walking test } \\
\text { Secondary } \\
\text { - Demographic data } \\
\text { - Neurological/clinical investigations } \\
\text { - Modified Roland Disabilty Questionnaire } \\
\text { - Visual analogue scale (VAS) for pain in back and leg } \\
\text { - Perceived recovery } \\
\text { - Short Form (SF)-36/30 } \\
\text { - Societal costs and utilities (European Organization for Research and Treatment of Cancer core } \\
\text { quality of life questionnaire (EuroQol-5D), visual analogue scale) } \\
\text { - Complications } \\
\text { - Reoperation incidence } \\
\text { - Operative data } \\
\text { - Imaging findings } \\
\text { - Participant's, neurologist's, neurosurgeon's, general practitioner's (GP's) preferences at baseline } \\
\text { - Timed-up and go test } \\
\text { - Short physical performance battery (SPPB) } \\
\text { - MicroFET (Force Evaluating and Testing) } \\
\text { - Grip strength } \\
\text { - Accelerometry }\end{array}$ \\
\hline
\end{tabular}


Overdevest 2011 (Continued)

Starting date

$\mathrm{N} / \mathrm{A}$

Contact information

Notes

NTR2216

\section{DATA AND ANALYSES}

Comparison 1. Decompression \pm fusion vs usual conservative care for Oswestry Disability Index

\begin{tabular}{lllll}
\hline $\begin{array}{l}\text { Outcome or subgroup } \\
\text { title }\end{array}$ & $\begin{array}{l}\text { No. of } \\
\text { studies }\end{array}$ & $\begin{array}{l}\text { No. of } \\
\text { partici- } \\
\text { pants }\end{array}$ & Statistical method & Effect size \\
\hline $\begin{array}{l}1 \text { Oswestry Disability In- } \\
\text { dex }\end{array}$ & 2 & & Mean Difference (IV, Random, 95\% Cl) & Subtotals only \\
\hline 1.16 months & 2 & 349 & Mean Difference (IV, Random, 95\% Cl) & $-3.66[-10.12,2.80]$ \\
\hline 1.21 year & 2 & 340 & Mean Difference (IV, Random, 95\% Cl) & $-6.17[-15.02,2.67]$ \\
\hline 1.32 years & 2 & 315 & Mean Difference (IV, Random, 95\% Cl) & $-4.43[-7.91,-0.96]$ \\
\hline 2 Pain & 1 & & Risk Ratio (M-H, Fixed, 95\% Cl) & Subtotals only \\
\hline 2.13 months & 1 & 31 & Risk Ratio (M-H, Fixed, 95\% Cl) & $1.38[0.22,8.59]$ \\
\hline 2.24 years & 1 & 30 & Risk Ratio (M-H, Fixed, 95\% Cl) & $7.5[1.00,56.48]$ \\
\hline 2.310 years & 1 & 29 & Risk Ratio (M-H, Fixed, 95\% Cl) & $4.09[0.95,17.58]$
\end{tabular}

Analysis 1.1. Comparison 1 Decompression \pm fusion vs usual conservative care for Oswestry Disability Index, Outcome 1 Oswestry Disability Index.

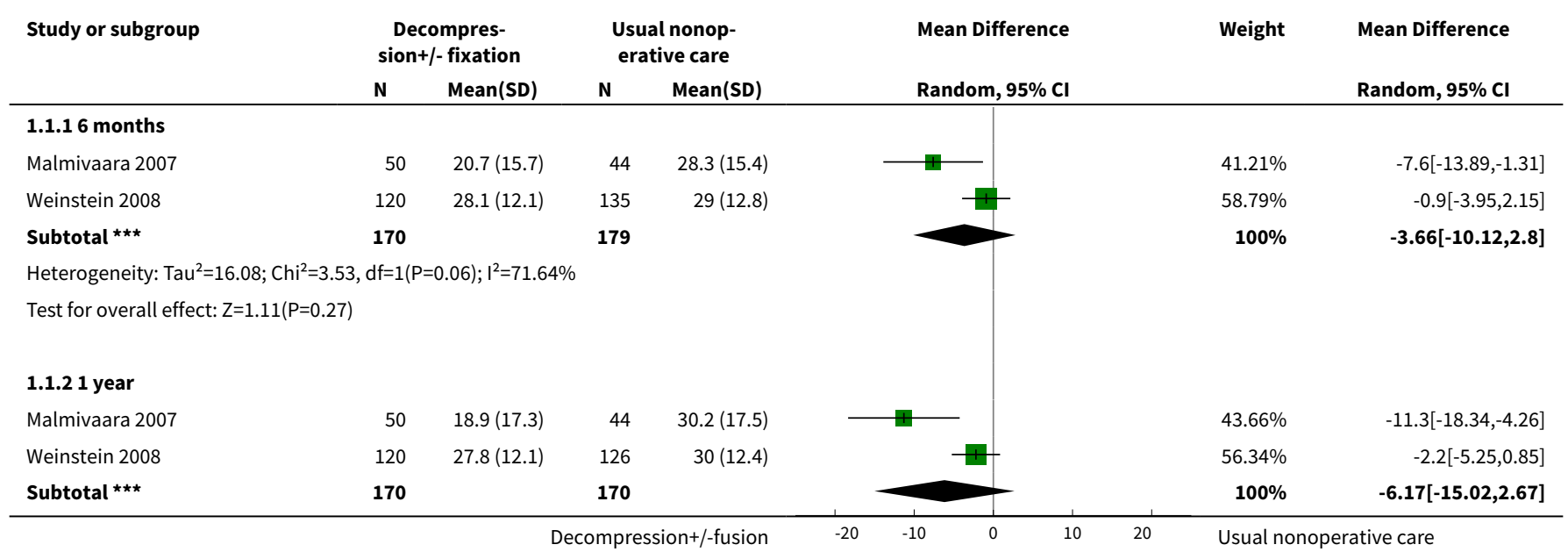




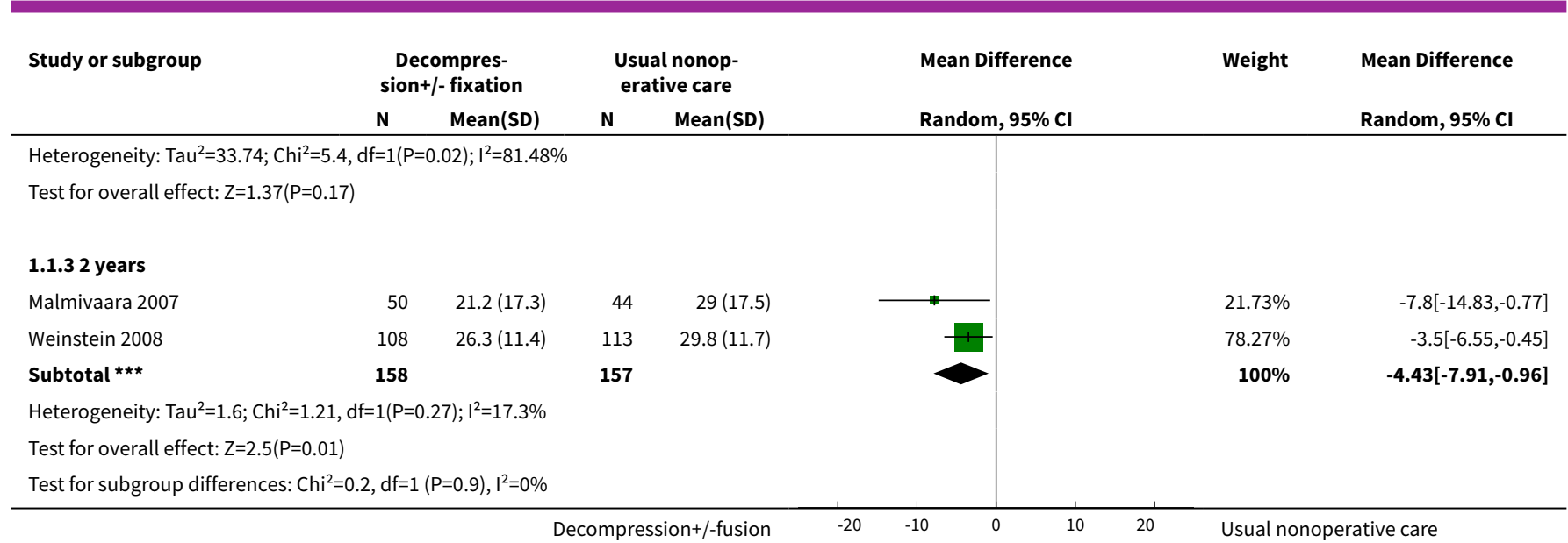

\section{Analysis 1.2. Comparison 1 Decompression \pm fusion vs usual conservative care for Oswestry Disability Index, Outcome 2 Pain.}

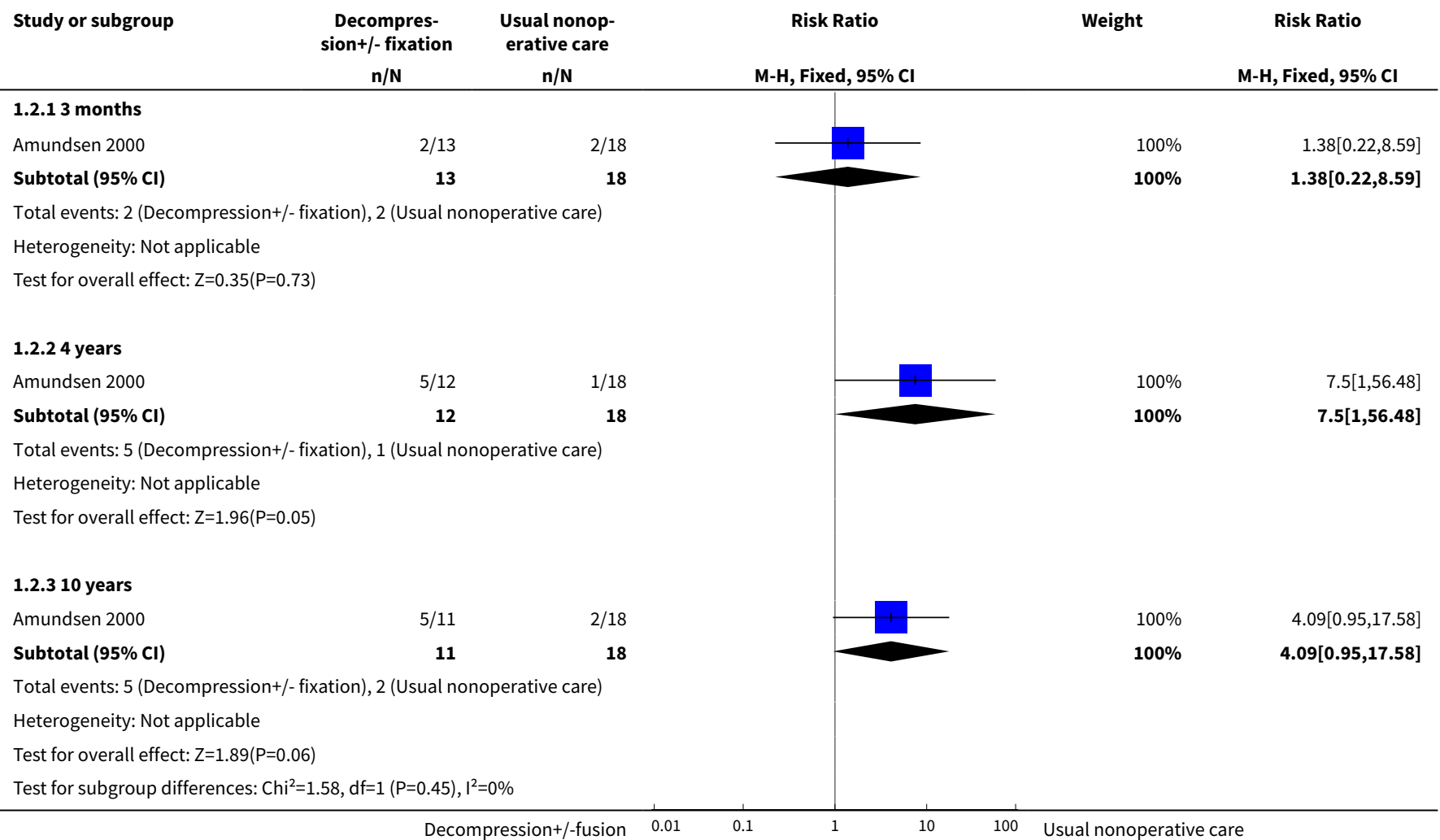


Comparison 2. Epidural steroid injection vs decompression with or without fusion

\begin{tabular}{llllll}
\hline Outcome or subgroup title & $\begin{array}{l}\text { No. of } \\
\text { studies }\end{array}$ & $\begin{array}{l}\text { No. of } \\
\text { partici- } \\
\text { pants }\end{array}$ & Statistical method & Effect size \\
\hline 1 Oswestry Disability Index & 1 & 38 & Mean Difference (IV, Fixed, 95\% CI) & $5.7[0.57,10.83]$ \\
\hline 1.16 weeks & 1 & 38 & Mean Difference (IV, Fixed, 95\% CI) & $5.7[0.57,10.83]$ \\
\hline 2 Visual Analogue Scale & 1 & 38 & Mean Difference (IV, Fixed, 95\% CI) & $2.4[1.92,2.88]$ \\
\hline 2.16 weeks & 1 & 38 & Mean Difference (IV, Fixed, 95\% Cl) & $2.4[1.92,2.88]$ \\
\hline $\begin{array}{l}3 \text { Zurich Claudication Question- } \\
\text { naire }\end{array}$ & 1 & 38 & Mean Difference (IV, Fixed, 95\% CI) & $-0.60[-0.77,-0.43]$ \\
\hline 3.16 weeks & 1 & 38 & Mean Difference (IV, Fixed, 95\% CI) & $-0.60[-0.77,-0.43]$ \\
\hline
\end{tabular}

\section{Analysis 2.1. Comparison 2 Epidural steroid injection vs decompression} with or without fusion, Outcome 1 Oswestry Disability Index.

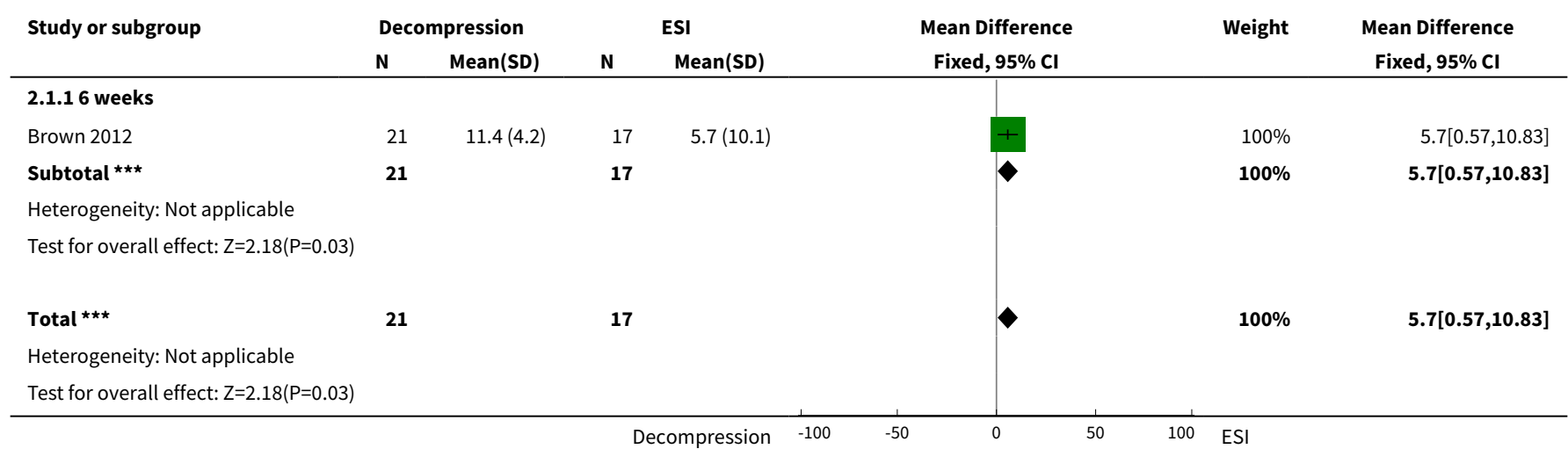

Analysis 2.2. Comparison 2 Epidural steroid injection vs decompression with or without fusion, Outcome 2 Visual Analogue Scale.

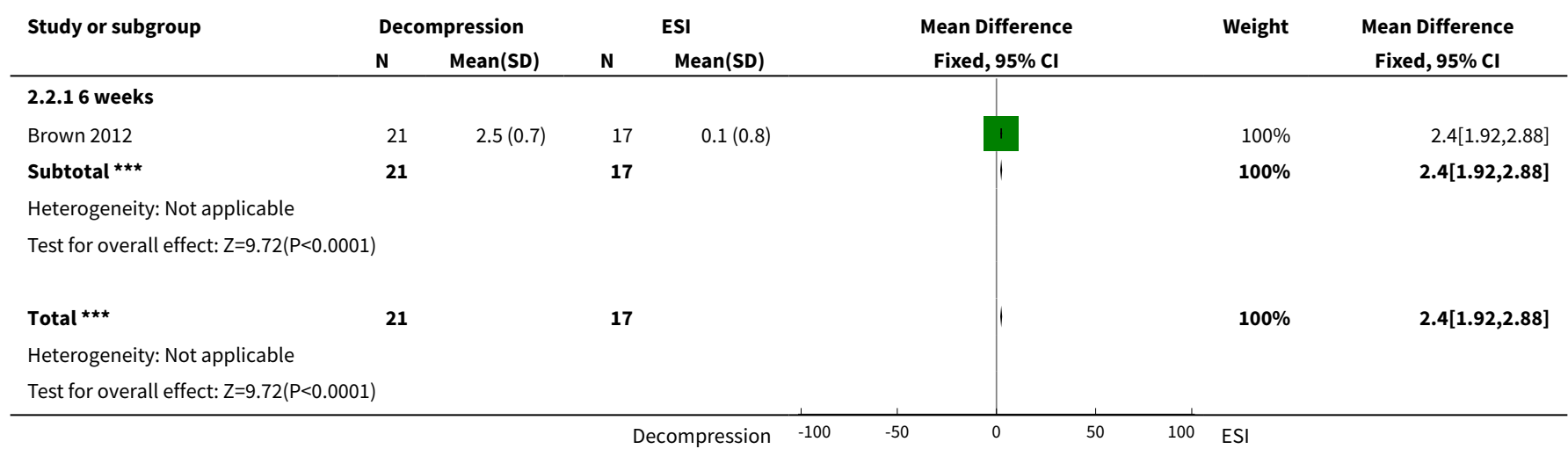


Analysis 2.3. Comparison 2 Epidural steroid injection vs decompression with or without fusion, Outcome 3 Zurich Claudication Questionnaire.

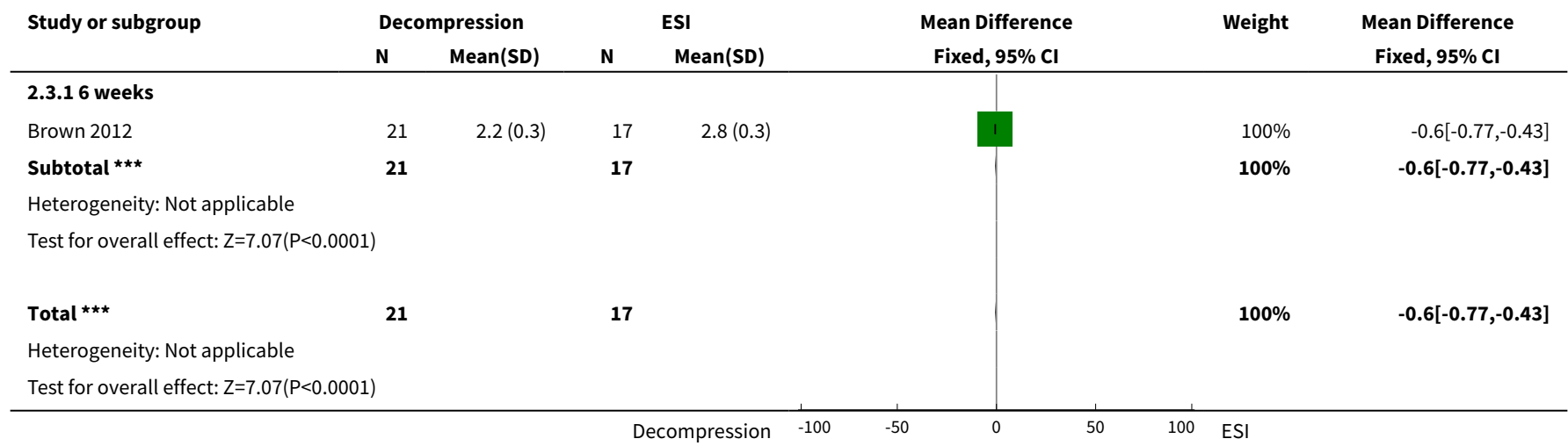

\section{APPENDICES}

\section{Appendix 1. MEDLINE and other search strategies}

\section{CENTRAL}

Last searched 11 February 2015.

\#1 MeSH descriptor: [Spinal Stenosis] explode all trees

\#2 spin* near/5 stenosis

\#3 lumb* near/5 stenosis

\#4 neurogenic claudication

\#5 MeSH descriptor: [Spinal Osteophytosis] explode all trees

\#6 MeSH descriptor: [Spondylosis] explode all trees

\#7 lumb* near/5 spondyl*

\#8 MeSH descriptor: [Cauda Equina] explode all trees

\#9 lumbar radicular pain

$\# 10 \# 1$ or \#2 or \#3 or \#4 or \#5 or \#6 or \#7 or \#8 or \#9

\#11 \#10 Publication Year from 2012 to 2014, in Trials

\section{MEDLINE}

Last searched 11 February 2015.

Line 3 was added to the 2015 search.

1. randomized controlled trial.pt.

2. controlled clinical trial.pt.

3. pragmatic clinical trial.pt.

4. randomized.ab.

5. placebo.ab,ti.

6. drug therapy.fs. 
7. randomly.ab,ti.

8. trial.ab,ti.

9. groups.ab,ti.

10.or/1-9

11.(animals not (humans and animals)).sh.

12.10 not 11

13.exp Constriction, Pathologic/

14.limit 13 to $y r=" 1976$ - 1982"

15.exp Lumbar Vertebrae/

16.limit 15 to $y r=" 1966$ - 1982"

17.exp Spinal Canal/

18.limit 17 to $y r=" 1966$ - 1982"

19.exp Spinal Diseases/

20.limit 19 to $y r=" 1966$ - 1982"

21.exp Spinal Stenosis/

22.spinal stenosis.mp.

23.(lumbar adj5 stenosis).mp. [mp=title, abstract, original title, name of substance word, subject heading word, keyword heading word, protocol supplementary concept word, rare disease supplementary concept word, unique identifier]

24.(spin* adj5 stenosis).mp. [mp=title, abstract, original title, name of substance word, subject heading word, keyword heading word, protocol supplementary concept word, rare disease supplementary concept word, unique identifier]

25.neurogenic claudication.mp.

26.exp Spinal Osteophytosis/

27.exp Spondylosis/

28.(lumb* adj5 spondy $\left.{ }^{\star}\right) \cdot m p$. [mp=title, abstract, original title, name of substance word, subject heading word, keyword heading word, protocol supplementary concept word, rare disease supplementary concept word, unique identifier]

29.exp Cauda Equina/

30. lumbar radicular pain.mp.

31.28 or 26 or 29 or 22 or 27 or 18 or 21 or 16 or 23 or 25 or 14 or 20 or 24 or 30

32.12 and 31

33. limit 32 to $y r=2012-2015$

34. limit 32 to ed=20121001-20150211

35.33 or 34

\section{MEDLINE In-Process \& Other Non-Indexed Citations}

Last searched 11 February 2015.

1. randomized controlled trial.pt.

2. controlled clinical trial.pt.

3. pragmatic clinical trial.pt.

4. randomized.ab.

5. placebo.ab,ti.

6. drug therapy.fs.

7. randomly.ab,ti.

8. trial.ab,ti.

9. groups.ab,ti.

10.or/1-9

11.(animals not (humans and animals)).sh.

12.10 not 11

13.exp Constriction, Pathologic/

14.limit 13 to $y r=" 1976$ - 1982"

15.exp Lumbar Vertebrae/

16.limit 15 to yr="1966 - 1982"

17.exp Spinal Canal/ 
18.limit 17 to $y r=" 1966$ - 1982"

19.exp Spinal Diseases/

20.limit 19 to $y r=" 1966$ - 1982"

21.exp Spinal Stenosis/

22.spinal stenosis.mp.

23.(lumbar adj5 stenosis).mp. [mp=title, abstract, original title, name of substance word, subject heading word, keyword heading word, protocol supplementary concept word, rare disease supplementary concept word, unique identifier]

24.(spin* adj5 stenosis).mp. [mp=title, abstract, original title, name of substance word, subject heading word, keyword heading word, protocol supplementary concept word, rare disease supplementary concept word, unique identifier]

25. neurogenic claudication.mp.

26.exp Spinal Osteophytosis/

27.exp Spondylosis/

28.(lumb* adj5 spondy $\left.{ }^{\star}\right) \cdot m p$. [mp=title, abstract, original title, name of substance word, subject heading word, keyword heading word, protocol supplementary concept word, rare disease supplementary concept word, unique identifier]

29.exp Cauda Equina/

30. lumbar radicular pain.mp.

31.28 or 26 or 29 or 22 or 27 or 18 or 21 or 16 or 23 or 25 or 14 or 20 or 24 or 30

32.12 and 31

\section{EMBASE}

Last searched 19 February 2015.

The study design and animal studies filter were revised in 2015.

1. Randomized Controlled Trial/

2. Controlled clinical trial/

3. Controlled Study/

4. Double Blind Procedure/

5. or/1-4

6. allocat\$.mp.

7. assign\$.mp.

8. compar\$.mp.

9. placebo\$.mp.

10.prospectiv\$.mp.

11.random $\$ \mathrm{mp}$.

12.((singl\$ or doubl\$ or trebl\$ or tripl\$) adj25 (blind\$ or mask\$)).mp.

13.trial.mp.

14.or/6-13

15.5 or 14

16.exp animals/ or exp invertebrate/ or animal experiment/ or animal model/ or animal tissue/ or animal cell/ or nonhuman/

17.human/ or normal human/ or human cell/

18.16 and 17

19.16 not 18

20.15 not 19

21.exp vertebral canal stenosis/

22.(spin* adj5 stenosis).mp. [mp=title, abstract, subject headings, heading word, drug trade name, original title, device manufacturer, drug manufacturer, device trade name, keyword]

23.(lumbar adj5 stenosis).mp. [mp=title, abstract, subject headings, heading word, drug trade name, original title, device manufacturer, drug manufacturer, device trade name, keyword]

24.(neurogenic adj2 claudication).mp. [mp=title, abstract, subject headings, heading word, drug trade name, original title, device manufacturer, drug manufacturer, device trade name, keyword]

25.(Spin* adj2 Osteophytosis).mp. [mp=title, abstract, subject headings, heading word, drug trade name, original title, device manufacturer, drug manufacturer, device trade name, keyword]

26.exp cauda equina/ 
27.lumbar radicular pain.mp.

28. (lumb* adj5 spondyl $\left.{ }^{\star}\right) \cdot m p$. [mp=title, abstract, subject headings, heading word, drug trade name, original title, device manufacturer, drug manufacturer, device trade name, keyword]

29.exp spondylosis/

30.spondylolisthesis/

31.or/21-30

32.20 and 31

33. limit 32 to $y r=2012-2015$

34. limit 32 to em $=201240-201507$

35.33 or 34

October 2012 search strategy

1. Clinical Article/

2. exp Clinical Study/

3. Clinical Trial/

4. Controlled Study/

5. Randomized Controlled Trial/

6. Major Clinical Study/

7. Double Blind Procedure/

8. Multicenter Study/

9. Single Blind Procedure/

10.Phase 3 Clinical Trial/

11.Phase 4 Clinical Trial/

12.crossover procedure/

13. placebo/

14.or/1-13

15.allocat\$.mp.

16.assign\$.mp.

17.blind\$.mp.

18. (clinic\$ adj25 (study or trial)).mp.

19.compar\$.mp.

20.control\$.mp.

21.cross?over.mp.

22. factorial\$.mp.

23.follow?up.mp.

24. placebo\$.mp.

25. prospectiv\$.mp.

26.random $\$$.mp.

27. ((singl\$ or doubl\$ or trebl\$ or tripl\$) adj25 (blind\$ or mask\$)).mp.

28.trial.mp.

29. (versus or vs).mp.

30.or/15-29

31.14 and 30

32.human/

33.Nonhuman/

34.exp ANIMAL/

35.Animal Experiment/

36.33 or 34 or 35

37.32 not 36

38.31 not 36

39.37 and 38

40.38 or 39 
41.exp vertebral canal stenosis/

42.(spin* adj5 stenosis).mp. [mp=title, abstract, subject headings, heading word, drug trade name, original title, device manufacturer, drug manufacturer name]

43.(lumbar adj5 stenosis).mp. [mp=title, abstract, subject headings, heading word, drug trade name, original title, device manufacturer, drug manufacturer name]

44.(neurogenic adj2 claudication).mp. [mp=title, abstract, subject headings, heading word, drug trade name, original title, device manufacturer, drug manufacturer name]

45.(Spin* adj2 Osteophytosis).mp. [mp=title, abstract, subject headings, heading word, drug trade name, original title, device manufacturer, drug manufacturer name]

46.exp cauda equina/

47. lumbar radicular pain.mp.

48.(lumb* adj5 spondy $\left.{ }^{\star}\right) \cdot m p$. [mp=title, abstract, subject headings, heading word, drug trade name, original title, device manufacturer, drug manufacturer name]

49.exp spondylosis/

50.spondylolisthesis/

51.or/41-50

52.40 and 51

\section{CINAHL}

Last searched 11 February 2015.

S40 S39 Limiters - Published Date: 20121001-20150231

S39 S28 AND S38

$\mathrm{S} 38 \mathrm{~S} 29$ or $\mathrm{S} 30$ or $\mathrm{S} 31$ or $\mathrm{S} 32$ or $\mathrm{S} 33$ or $\mathrm{S} 34$ or $\mathrm{S} 35$ or $\mathrm{S} 36$ or $\mathrm{S} 37$

S37 lumb* W5 spondyl*

S36 (MH "Spondylolisthesis") or (MH "Spondylolysis")

S35 "lumbar radicular pain"

S34 (MH "Cauda Equina")

S33 (MH "Spinal Osteophytosis")

S32 "neurogenic claudication"

S31 lumb* W5 stenosis

S30 spin* W5 stenosis

S29 (MH "Spinal Stenosis")

S28 S26 NOT S27

S27 (MH "Animals")

S26 S7 or S12 or S19 or S25

$\mathrm{S} 25 \mathrm{~S} 20$ or S21 or S22 or S23 or S24

S24 volunteer*

S23 prospectiv*

S22 control $^{*}$

S21 followup stud ${ }^{*}$

S20 follow-up stud ${ }^{*}$

$\mathrm{S} 19 \mathrm{~S} 13$ or $\mathrm{S} 14$ or $\mathrm{S} 15$ or $\mathrm{S} 16$ or $\mathrm{S} 17$ or $\mathrm{S} 18$ 
S18 (MH "Prospective Studies+")

S17 (MH "Evaluation Research+")

S16 (MH "Comparative Studies")

S15 latin square

S14 (MH "Study Design+")

S13 (MH "Random Sample")

$\mathrm{S} 12 \mathrm{~S} 8$ or $\mathrm{S} 9$ or S10 or S11

S11 random*

S10 placebo*

S9 (MH "Placebos")

S8 (MH "Placebo Effect")

$\mathrm{S} 7 \mathrm{~S} 1$ or $\mathrm{S} 2$ or $\mathrm{S} 3$ or $\mathrm{S} 4$ or $\mathrm{S} 5$ or $\mathrm{S} 6$

S6 triple-blind

S5 single-blind

S4 double-blind

S3 clinical W3 trial

S2 "randomi?ed controlled trial*"

S1 (MH "Clinical Trials+")

ICL

Last searched 11 February 2015.

S1, Publication Type:Clinical Trial

S2, Publication Type:Controlled Clinical Trial

S3, Publication Type:Randomized Controlled Trial

S4 All Fields:random* OR All Fields:placebo* OR All Fields:sham

S5 All Fields:versus OR All Fields:vs

S6 All Fields:"clinical trial" OR All Fields:"controlled trial"

S7 All Fields:double-blind OR All Fields:"double blind"

S8 All Fields:single-blind OR All Fields:"single blind"

S9 , Publication Type:Clinical Trial OR , Publication Type:Controlled Clinical Trial OR , Publication Type:Randomized Controlled Trial OR All Fields:random* OR All Fields:placebo* OR All Fields:sham OR All Fields:versus OR All Fields:vs OR All Fields:"clinical trial" OR All Fields:"controlled trial" OR All Fields:double-blind OR All Fields:"double blind" OR All Fields:single-blind OR All Fields:"single blind"

S10 Subject:"Spinal Stenosis" OR All Fields:spinal stenosis

S11 Subject:"Spinal Osteophytosis" OR Subject:"Spondylosis" OR Subject:"Spondylolisthesis"

S12 Subject:"Cauda Equina" OR All Fields:"lumbar radicular pain"

S13 Subject:"Spinal Stenosis" OR All Fields:spinal stenosis OR Subject:"Spinal Osteophytosis" OR Subject:"Spondylosis" OR Subject:"Spondylolisthesis" OR Subject:"Cauda Equina" OR All Fields:"lumbar radicular pain" 
S14, Publication Type:Clinical Trial OR , Publication Type:Controlled Clinical Trial OR , Publication Type:Randomized Controlled Trial OR All Fields:random* OR All Fields:placebo* OR All Fields:sham OR All Fields:versus OR All Fields:vs OR All Fields:"clinical trial" OR All Fields:"controlled trial" OR All Fields:double-blind OR All Fields:"double blind" OR All Fields:single-blind OR All Fields:"single blind" AND Subject:"Spinal Stenosis" OR All Fields:spinal stenosis OR Subject:"Spinal Osteophytosis" OR Subject:"Spondylosis" OR Subject:"Spondylolisthesis" OR Subject:"Cauda Equina" OR All Fields:"lumbar radicular pain"

S15, Year: from 2012 to 2015

S16, Publication Type:Clinical Trial OR , Publication Type:Controlled Clinical Trial OR , Publication Type:Randomized Controlled Trial OR All Fields:random* OR All Fields:placebo* OR All Fields:sham OR All Fields:versus OR All Fields:vs OR All Fields:"clinical trial" OR All Fields:"controlled trial" OR All Fields:double-blind OR All Fields:"double blind" OR All Fields:single-blind OR All Fields:"single blind" AND Subject:"Spinal Stenosis" OR All Fields:spinal stenosis OR Subject:"Spinal Osteophytosis" OR Subject:"Spondylosis" OR Subject:"Spondylolisthesis" OR Subject:"Cauda Equina" OR All Fields:"lumbar radicular pain" AND , Year: from 2012 to 2015

\section{PEDro}

Last searched 11 February 2015. In the October 2012 search, Method was limited to Clinical Trial.

Abstract and title: stenosis

AND

Body part: lumbar spine, sacroiliac joint or pelvis

AND

Method: no limit

\section{ClinicalTrials.gov}

Last searched 11 February 2015.

lumbar stenosis OR spinal stenosis OR spine stenosis

\section{WHO ICTRP}

Last searched 11 February 2015.

lumbar stenosis OR spinal stenosis OR spine stenosis

\section{PubMed}

Last searched 11 February 2015.

((lumbar stenosis OR spine stenosis OR spinal stenosis) AND (pubstatusaheadofprint OR publisher[sb] OR pubmednotmedline[sb]))

\section{CBN trials register in CRS}

Last searched 11 February 2015.

\#1 (lumbar stenosis OR spine stenosis OR spinal stenosis) AND (INREGISTER)

\section{Appendix 2. Criteria for judging risk of bias}

\section{Random sequence generation (selection bias)}

\section{Selection bias (biased allocation to interventions) due to inadequate generation of a randomised sequence}

Risk of selection bias is low if investigators describe a random component in the sequence generation process such as referring to a random number table, using a computer random number generator, tossing a coin, shuffling cards or envelopes, throwing dice, drawing lots and minimising (minimisation may be implemented without a random element; this is considered equivalent to being random).

Risk of selection bias is high if investigators describe a non-random component in the sequence generation process such as sequence generated by odd or even date of birth, date (or day) of admission or hospital or clinic record number; or allocation by judgement of the clinician, preference of the participant, results of a laboratory test or a series of tests or availability of the intervention. 


\section{Allocation concealment (selection bias)}

\section{Selection bias (biased allocation to interventions) due to inadequate concealment of allocations before assignment}

Risk of selection bias is low if participants and investigators enrolling participants could not foresee assignment because one of the following, or an equivalent method, was used to conceal allocation: central allocation (including telephone, Web-based and pharmacycontrolled randomisation); sequentially numbered drug containers of identical appearance; or sequentially numbered, opaque, sealed envelopes.

Risk of bias is high if participants or investigators enrolling participants could possibly foresee assignments and thus introduce selection bias such as allocation based on using an open random allocation schedule (e.g. a list of random numbers); assignment envelopes without appropriate safeguards (e.g. if envelopes were unsealed or non-opaque, or were not sequentially numbered); alternation or rotation; date of birth; case record number; or other explicitly unconcealed procedures.

\section{Blinding of participants}

\section{Performance bias due to knowledge of allocated interventions by participants during the study}

Risk of performance bias is low if blinding of participants was ensured and it was unlikely that blinding could have been broken; or if no blinding or incomplete blinding was provided but review authors judged that the outcome is not likely to be influenced by lack of blinding.

\section{Blinding of personnel/care providers (performance bias)}

\section{Performance bias due to knowledge of allocated interventions by personnel/care providers during the study}

Risk of performance bias is low if blinding of personnel was ensured and it was unlikely that blinding could have been broken; or if no blinding or incomplete blinding was provided but review authors judged that the outcome is not likely to be influenced by lack of blinding.

\section{Blinding of outcome assessor (detection bias)}

\section{Detection bias due to knowledge of allocated interventions by outcome assessors}

Risk of detection bias is low if blinding of the outcome assessment was ensured and it was unlikely that blinding could have been broken; or if no blinding or incomplete blinding was provided but review authors judged that the outcome is not likely to be influenced by lack of blinding, or:

- for participant-reported outcomes in which the participant was the outcome assessor (e.g. pain, disability): low risk of bias for outcome assessors if low risk of bias for participant blinding (Boutron 2005);

- for outcome criteria that are clinical or therapeutic events that will be determined by the interaction between patients and care providers (e.g. co-interventions, length of hospitalisation, treatment failure) and in which the care provider was the outcome assessor: low risk of bias for outcome assessors if low risk of bias for care providers (Boutron 2005); and

- for outcome criteria assessed from data obtained from medical forms: low risk of bias if treatment or adverse effects of treatment could not be noticed in the extracted data (Boutron 2005).

\section{Incomplete outcome data (attrition bias)}

\section{Attrition bias due to quantity, nature or handling of incomplete outcome data}

Risk of attrition bias is low if no outcome data were missing; reasons for missing outcome data were unlikely to be related to the true outcome (for survival data, censoring unlikely to introduce bias); missing outcome data were balanced in quantity, with similar reasons for missing data across groups; for dichotomous outcome data, the proportion of missing outcomes compared with the observed event risk was not sufficient to have a clinically relevant impact on the intervention effect estimate; for continuous outcome data, the plausible effect size (differences in means or standardised differences in means) among missing outcomes was not sufficient to have a clinically relevant impact on observed effect size, or missing data were imputed using appropriate methods (if dropouts are very large, imputation using even 'acceptable' methods may still suggest high risk of bias) (van Tulder 2003). Percentages of withdrawals and dropouts should not exceed $20 \%$ for short-term follow-up and 30\% for long-term follow-up and should not lead to substantial bias (these percentages are commonly used but are arbitrary and are not supported by literature) (van Tulder 2003).

\section{Selective reporting (reporting bias)}

\section{Reporting bias due to selective outcome reporting}

Risk of reporting bias is low if the study protocol is available and all of the study's prespecified (primary and secondary) outcomes of interest in the review were reported in the prespecified way, or if the study protocol is not available but published reports clearly include all expected outcomes, including those that were prespecified (convincing text of this nature may be uncommon).

Risk of reporting bias is high if not all of the study's prespecified primary outcomes were reported; one or more primary outcomes were reported using measurements, analysis methods or subsets of the data (e.g. subscales) that were not prespecified; one or more reported primary outcomes were not prespecified (unless clear justification for their reporting is provided, such as an unexpected adverse effect); 
one or more outcomes of interest in the review were reported incompletely so that they cannot be entered in a meta-analysis; the study report failed to include results for a key outcome that would be expected to have been reported for such a study.

Group similarity at baseline (selection bias)

Bias due to dissimilarity at baseline for the most important prognostic indicators.

Risk of bias is low if groups were similar at baseline for demographic factors, value of main outcome measure(s) and important prognostic factors (examples in the field of back and neck pain include duration and severity of complaints, vocational status and percentage of participants with neurological symptoms) (van Tulder 2003).

\section{Co-interventions (performance bias)}

\section{Bias because co-interventions were different across groups}

Risk of bias is low if no co-interventions were provided, or if they were similar between index and control groups (van Tulder 2003).

\section{Compliance (performance bias)}

\section{Bias due to inappropriate compliance with interventions across groups}

Risk of bias is low if compliance with the interventions was acceptable based on reported intensity or dosage, duration, number and frequency for both index and control intervention(s). For single-session interventions (e.g. surgery), this item is irrelevant (van Tulder 2003).

\section{Intention-to-treat analysis}

Risk of bias is low if all randomly assigned participants were reported and analysed in the group to which they were allocated by randomisation.

\section{Timing of outcome assessments (detection bias)}

\section{Bias because important outcomes were not measured at the same time across groups}

Risk of bias is low if all important outcome assessments for all intervention groups were measured at the same time (van Tulder 2003).

\section{Other bias}

\section{Bias due to problems not covered elsewhere in the table}

Risk of bias is low if the study appears to be free of other sources of bias not addressed elsewhere (e.g. study funding).

\section{Appendix 3. Questions for clinical relevance}

- Are participants described in detail so that you can decide whether they are comparable with patients seen in your practice?

- Are interventions and treatment settings described well enough that you can provide the same for your patients?

- Were all clinically relevant outcomes measured and reported?

- Is the size of the effect clinically important?

- Are likely treatment benefits worth potential harms?

\section{CONTRIBUTIONS OFAUTHORS}

\section{Substantial contributions to conception and design}

Zaina F, Tomkins-Lane C, Carragee E, Negrini S.

\section{Drafting of the protocol}

Zaina F, Tomkins-Lane C.

\section{Final approval of the version to be published}

Zaina F, Tomkins-Lane C, Carragee E, Negrini S.

\section{DECLARATIONSOF INTEREST}

We have nothing to disclose. 


\section{SOURCES OFSUPPORT}

\section{Internal sources}

- None, Other.

\section{External sources}

- No sources of support supplied

\section{DIFFERENCES BETWEEN PROTOCOLAND REVIEW}

\section{Subgroup analysis and investigation of heterogeneity}

Given that we conducted the meta-analysis using only two studies, it was not appropriate to conduct subgroup analyses (Malmivaara 2007; Weinstein 2008).

\section{Sensitivity analysis}

Studies included in the meta-analysis had similar risk of bias; therefore, we did not expect differences in treatment effect based on bias, and we did not conduct sensitivity analyses (Malmivaara 2007; Weinstein 2008).

\section{N D EX TERMS}

\section{Medical Subject Headings (MeSH)}

^Braces; *Decompression, Surgical [adverse effects]; *Exercise Therapy; *Spinal Fusion [adverse effects]; Injections, Epidural; Laminectomy; Lumbosacral Region; Pain Measurement; Randomized Controlled Trials as Topic; Spinal Cord Compression [surgery]; Spinal Stenosis [surgery] [*therapy]

\section{MeSH check words}

Aged; Female; Humans; Male; Middle Aged 